\title{
Article \\ Transcriptome Analysis of Seed Weight Plasticity in Brassica napus
}

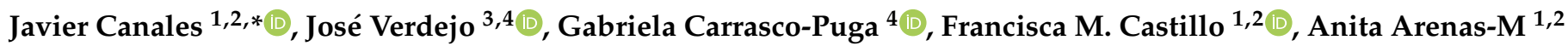 \\ and Daniel F. Calderini ${ }^{4, *}$ (D) \\ 1 Institute of Biochemistry and Microbiology, Faculty of Sciences, Universidad Austral de Chile, \\ 5110566 Valdivia, Chile; castillo.francisca88@gmail.com (F.M.C.); ana.arenas@uach.cl (A.A.-M.) \\ 2 ANID-Millennium Science Initiative Program-Millennium Institute for Integrative Biology (iBio), \\ 8331150 Santiago, Chile \\ 3 Graduate School, Faculty of Agricultural Sciences, Universidad Austral de Chile, 5110566 Valdivia, Chile; \\ jose.verdejo.a@outlook.com \\ 4 Plant Production and Plant Protection Institute, Faculty of Agricultural Sciences, Universidad Austral de \\ Chile, 5110566 Valdivia, Chile; gacarcl@gmail.com \\ * Correspondence: javier.canales@uach.cl (J.C.); danielcalderini@uach.cl (D.F.C.)
}

Citation: Canales, J.; Verdejo, J.;

Carrasco-Puga, G.; Castillo, F.M.;

Arenas-M, A.; Calderini, D.F.

Transcriptome Analysis of Seed

Weight Plasticity in Brassica napus. Int.

J. Mol. Sci. 2021, 22, 4449.

https://doi.org/10.3390/ijms22094449

Academic Editor: Frank M. You

Received: 24 March 2021

Accepted: 23 April 2021

Published: 24 April 2021

Publisher's Note: MDPI stays neutral with regard to jurisdictional claims in published maps and institutional affiliations.

Copyright: (c) 2021 by the authors. Licensee MDPI, Basel, Switzerland. This article is an open access article distributed under the terms and conditions of the Creative Commons Attribution (CC BY) license (https:// creativecommons.org/licenses/by/ $4.0 /)$.

\begin{abstract}
A critical barrier to improving crop yield is the trade-off between seed weight (SW) and seed number (SN), which has been commonly reported in several crops, including Brassica napus. Despite the agronomic relevance of this issue, the molecular factors involved in the interaction between SW and SN are largely unknown in crops. In this work, we performed a detailed transcriptomic analysis of 48 seed samples obtained from two rapeseed spring genotypes subjected to different source-sink (S-S) ratios in order to examine the relationship between SW and SN under different field conditions. A multifactorial analysis of the RNA-seq data was used to identify a group of 1014 genes exclusively regulated by the S-S ratio. We found that a reduction in the S-S ratio during seed filling induces the expression of genes involved in sucrose transport, seed weight, and stress responses. Moreover, we identified five co-expression modules that are positively correlated with SW and negatively correlated with SN. Interestingly, one of these modules was significantly enriched in transcription factors (TFs). Furthermore, our network analysis predicted several NAC TFs as major hubs underlying SW and SN compensation. Taken together, our study provides novel insights into the molecular factors associated with the SW-SN relationship in rapeseed and identifies TFs as potential targets when improving crop yield.
\end{abstract}

Keywords: Brassica napus; seed weight; seed number; gene co-expression; network analysis; transcriptomics; source-sink

\section{Introduction}

Research on the physiological and molecular clues in controlling seed weight (SW) has increased in recent years in model plants and staple food crops, driven by the challenge of developing high-yield varieties in order to attain food security and quality seed traits under sustainable production systems [1]. Therefore, gains in genetic yield potential are urgently needed to meet growing demands [2]. Globally, rapeseed (Brassica napus L.) is the third most important oilseed crop, after palm and soybean, used for oil production, animal feed, and biofuel [3]. In oil crops, the rising demand for biofuels has resulted in exponential growth, reaching an estimated global production of 612 million $\mathrm{Mg}$ across oil crops in 2018 [4]. This growth has also been evident in rapeseed production since 1980, reaching 75 million $\mathrm{Mg}$ in 2019 [5]. However, the stagnation of the yield in rapeseed has been shown in countries such as the United Kingdom, Brazil, Finland, Sweden, and the Czech Republic [6-8]. Therefore, new strategies aimed at increasing seed yield are urgently needed. To this end, an integrated approach combining physiology and gene mining 
knowledge should allow us to uncover key associations that determine complex traits such as yield.

Seed weight is a conservative plant trait across grain crops, showing high heritability $[6,9,10]$. In addition to these features, the SW of rapeseed has also shown narrower plasticity than other crops, such as cereals, e.g., wheat and barley [11], and oil crops, such as sunflower [12,13]. However, it has been recently demonstrated that the SW of rapeseed can fully compensate for decreases in seed number (SN) under source reduction at flowering [14]. In this regard, other work has also shown the compensation, though partial, for the SN decrease through increased SW around flowering $[15,16]$. This background offers an outstanding opportunity to study the physiological and molecular bases of SW regulation in rapeseed. Different genes have been reported to be involved in SW and seed size determination, such as key genes involved in the regulation of cell size and cell number of seeds, highlighting the ubiquitin-proteasome pathway [17]; phytohormone biosynthesis/signaling $[18,19]$; transcriptional regulatory factors, such as APETALA2 and MADS-box [20]; sugar signaling [21]. Recently, a detailed transcriptome analysis of two Brassica rapa genotypes with contrasting seed sizes in seven stages of seed development has been reported, identifying a group of cell cycle-related genes connected to variation in seed size [22]. However, these studies have mostly focused on seed size or SW under controlled conditions and, more importantly, without the evaluation of the key SN-SW compensation shown by this crop.

Brassicas are the most closely related crops to the model plant species Arabidopsis thaliana, one of the most extensively studied species in the world. The sequencing of the genome of several Brassicas has provided a key opportunity to harness the rich knowledge obtained in Arabidopsis and to transfer it to staple food crops [23].

The evidence that a reduction in SN can be fully or partially compensated by SW support the high plasticity of rapeseed, previously reported [14-16]. Therefore, in order to understand the SW plasticity in rapeseed, an integrated physiological and molecular approach was carried out in this study using the experiments with spring rapeseed that we previously reported [16]. In that work, we found that the source reduction from the beginning of flowering to 15 days after flowering (DAF) by shading added a new scenario to study the determinants of seed plasticity because the thousand seed weight (TSW) was enhanced, ranging from 15 to $39 \%$ in response to the seed number (SN) decrease of between 37 and 49\% [16]. Therefore, the reduction in SN was partially compensated for by SW, supporting the high plasticity of SW under source reduction previously reported [14-16]. Finally, our study aimed to use bioinformatics analysis to identify the genes associated with SN and SW compensation under field conditions, which may be helpful targets for yield improvement in rapeseed and other crops, breaking the extensively reported trade-off between the two major yield components. The feasibility of breaking this trade-off has been recently demonstrated in wheat [24].

\section{Results}

\subsection{Multivariate Analysis of RNA-Seq Data Uncovers the Main Factors Affecting Seed} Transcriptomes in Rapeseed under Field Conditions

In order to gain new insights into the molecular factors underlying SW plasticity in rapeseed under field conditions, we performed a detailed transcriptomic analysis of seed samples obtained from two spring genotypes (Lumen and Solar) subjected to different S-S ratios [16]. We extracted total RNA from seeds at two different times during seed filling to capture early and late responses to S-S ratio treatments (7 and 14 days after flowering, respectively). We obtained 1240 million reads from 48 samples comprising both genotypes, two S-S ratios from two sowing date treatments with three replicates. On average, each sample had 26 million reads, of which $73 \%$ were mapped to the Brassica napus reference transcriptome using kallisto software [25] (Figure S1). To interpret this large transcriptomics dataset, we designed a multivariate linear model testing whether the expression of a given gene could be explained by the seed response to the $\mathrm{S}-\mathrm{S}$ ratio (SS), genotype (G), developmental time (T), sowing date (SD), and the interaction of these 
factors. We fit all expressed genes with this full linear model using sleuth [26] (Figure 1A), and we found that the expression of $78.7 \%$ of the regulated genes $(27,353$ of 34,764 genes, Table S1) could be best explained by a single term. This indicates a low synergistic effect of the factors analyzed (Figure 1A). The only remarkable synergistic effect was found among $\mathrm{G}, \mathrm{T}$, and SD (4741 genes, Figure 1A and Table S1). In contrast, the response to the S-S ratio occurred independently from the sowing date (Figure 1A).

Then, we intersected all the significantly regulated genes uncovered by multivariate analysis to find the genes exclusively regulated by each factor. In addition, we filtered out all genes that were regulated by sowing date to reduce the environmental effect on the main factors. In this manner, we identified 9227, 6698, and 1014 genes exclusively regulated by T, G, and SS, respectively (Figure 1B and Table S1). The number of genes affected by two or more factors was low except for the cases of SS and T, which were higher than SS alone (Figure 1B).

A

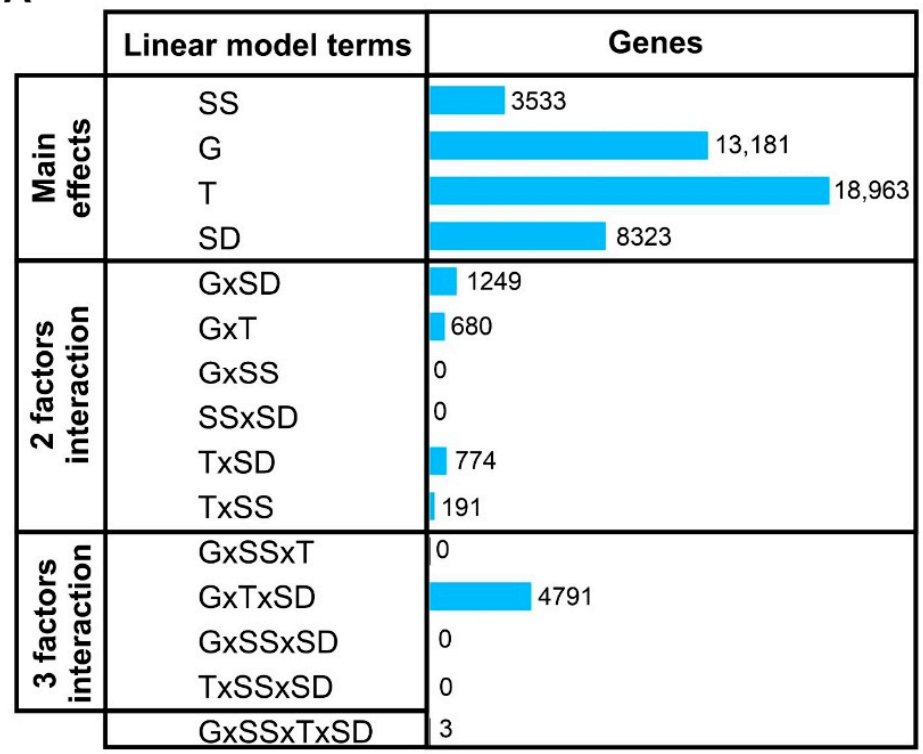

B

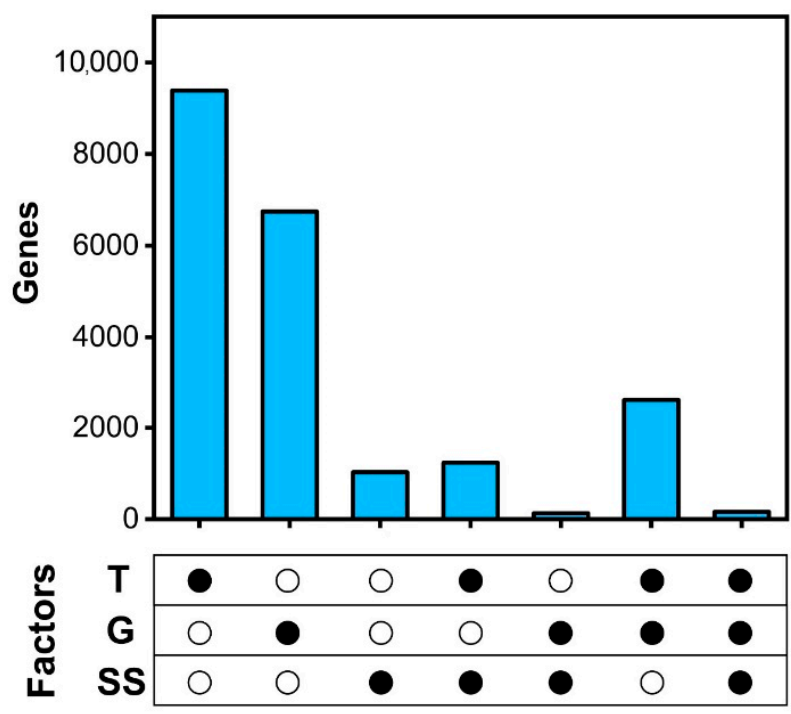

Figure 1. Multivariate analysis of the RNA-seq data obtained from seeds of two rapeseed hybrids grown under different source-sink ratios. (A) Multifactorial analysis showing how many genes were regulated by the S-S ratio (SS), genotype (G), developmental time (T), sowing date (SD), and the interaction of these factors (q-value < 0.01). An average of 26 million reads per sample were pseudo-aligned to the Brassica napus reference transcriptome using kallisto [25] and a fully mapped dataset was multivariate analyzed with the sleuth R package [26]. (B) An intersection analysis between genes regulated by the S-S ratio (SS), genotype (G), and developmental time (T). Genes significantly affected by SD or factors interactions were discarded from this analysis, which was performed using the SuperExactTest $\mathrm{R}$ package [27]. The black points indicate which factors affect the expression levels of the genes shown in the bar diagram.

\subsection{Genes Regulated by Development Time under Field Conditions Are Highly Enriched in Biological Processes Related to Seed Filling}

The experimental factor with a higher impact on the rapeseed transcriptome of seeds was developmental time. A detailed analysis of these genes is relevant because it provides information about the biological processes that are regulated during seed filling under field conditions. To identify genes preferentially expressed at the initial and middle stages of seed development, we performed a hierarchical clustering analysis of the genes exclusively regulated by time using the Pearson's correlation to measure the similarity among genes. In this manner, two clusters with similar sizes were identified (Figure 2). Cluster 1 is composed by 4173 genes for which the expression was higher at 7 DAF. This temporal expression pattern was consistent between genotypes, S-S ratio treatments, and sowing dates. To provide an overview of the biological pathways related to the genes of cluster 1, we performed a Gene Ontology (GO) overrepresentation analysis using BiNGO software [28]. 
We found that ribosomal assembly, histone modification, response to cadmium ion, and ovule development were the most enriched biological processes (Figure 2 and Table S2). Genes encoding for ribosomal proteins of the L10 and L34 families were expressed in higher levels at 7 DAF compared with at 14 DAF (Figure S2A). In addition, this set of genes was significantly enriched (q-value $<0.01$ ) in cell division-related GO terms including "DNA unwinding involved in replication", "regulation of DNA metabolic process", and "cell division" (Figure 2 and Table S2). In summary, the functional overview of these genes suggests that protein biosynthesis and cell division are biologically active functions during the early stages of seed development.

On the other hand, the expression levels of genes from cluster 2 were increased at $14 \mathrm{DAF}$. The most enriched biological processes were related to vacuole organization and Golgi vesicle-mediated transport (Figure S2B). In addition, we detected other significantly enriched GO terms related to lipid metabolism, such as the "acetyl-CoA biosynthetic process" or the "positive regulation of fatty acid biosynthetic process". These results suggest that genes related to lipid biosynthesis and storage protein trafficking are preferentially expressed during the mid-stages of seed development.

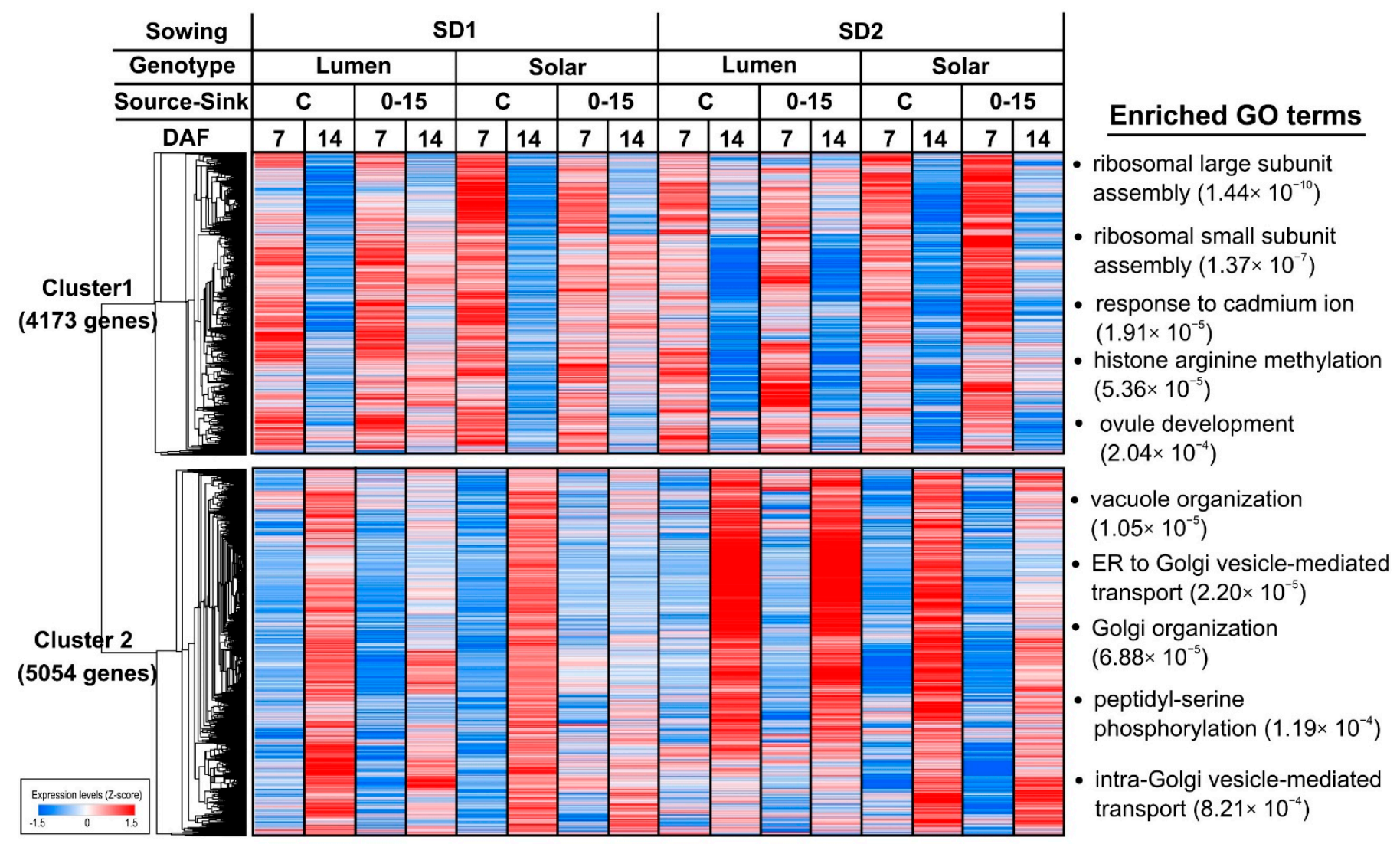

Figure 2. Genes exclusively regulated by developmental time are associated with seed filling. A heatmap showing the two major expression patterns of genes exclusively regulated by developmental time. Hierarchical clustering was performed based on Pearson correlation distances and average linkage using Morpheus software [29]. Each column of the heatmap represents the average expression of three biological replicates. The gene expression values for each gene were normalized by Z-score transformation. The top 5 enriched GO terms of the biological process domain are represented on the right side of each cluster. GO term enrichment analysis was performed by a hypergeometric test using BiNGO software [28]. FDRcorrected $p$-values are indicated for each GO term in brackets. $\mathrm{SD}=$ sowing date, $\mathrm{DAF}=$ days after flowering, $\mathrm{C}=\mathrm{control}$, $0-15=$ source to sink treatments performed from the beginning of flowering to 15 DAF. 
2.3. Reduction in the Source-Sink Ratio at Flowering Induces the Expression of Genes Involved in Stress Response and Seed Weight

Manipulations of the S-S ratio at the beginning of seed filling is a well-known experimental factor that impacts the seed yield components in rapeseed [14-16,30]. We previously showed that the shading treatment during seed filling reduces $\mathrm{SN}$ and SW in rapeseed $[14,16]$. To obtain information about the molecular factors underlying the negative effect of reducing the S-S ratio on SN and the positive impact on SW, we analyzed the expression patterns and functional annotations of 1014 genes exclusively affected by the shading treatment in more detail. Hierarchical clustering analysis showed that $90.4 \%$ of these genes (917 out 1014 genes) were induced by shading and that only 97 genes were downregulated by this treatment (Cluster 2 and Figure 3A). A Gene Ontology enrichment analysis reveals that several biological functions related to stress response, including the ABA signaling pathway were induced by the S-S ratio (Figure $3 \mathrm{~A}$ and Table S2). Moreover, we found sucrose transport between the most overrepresented biological processes, which includes genes associated with seed weight such as bidirectional sugar transporters such as SWEET 11 and SWEET 12. We selected three genes of the GO term "sucrose transport" to show the regulatory effect of shading treatment on the expression of these genes (Figure 3B). Interestingly, we found that genes regulated by the S-S ratio significantly intersect ( $p$-value $<0.05$ ) a list of well-known genes involved in SN and SW determination [31], which include SWEET genes, receptor-like protein kinase FERONIA (FER), or the RING-type protein with E3 ubiquitin ligase activity (DA2) [32] (Figure 3C).

\subsection{Gene Co-Expression Network Analysis Uncovers Novel Gene Modules Related to Seed Yield and Quality under Field Conditions}

In order to identify the key molecular drivers underlying important agronomic traits, such as $\mathrm{SN}$, SW, or oil concentration, we performed a weighted gene co-expression network analysis (WGCNA) [33] with all of the expressed genes at two different developmental times for rapeseed seeds and the physiological traits obtained from the same experiment [16] (Table S3). WGCNA allows for the identification of modules of highly co-expressed genes and relates the modules to external sample traits [33]. We excluded genes for which the mRNA levels were consistently low (less than 5 tpm in more than $90 \%$ of the samples) from this gene co-expression network analysis. In addition, we filtered out $25 \%$ of the genes with the lowest coefficients of variation at each developmental time since non-varying genes are less likely to have biologically relevant differences. In total, 25,963 and 27,025 genes meet these criteria at 7 and 14 DAF, respectively. After performing the WGCNA analysis with these genes, we obtained a gene co-expression network composed of 27 different modules at 7 DAF (Figure 4 and Table S4) and a second network with 17 different modules at 14 DAF (Figure 5 and Table S4). Therefore, the number of modules detected at $14 \mathrm{DAF}$ was remarkably lower than that during the early stage of seed development (7 DAF), suggesting that the transcriptome complexity is higher during initial stages of the seed filling period.

In the 7 DAF network, we found that 11 out of 27 modules had a significant correlation ( $p$-value $<0.01)$ with at least one physiological trait (Figure 4A). Nonsignificant correlated modules with physiological traits were discarded for further analyses. The turquoise, blue, yellow, and red modules were the biggest modules, with more than 500 genes each (Figure 4B). Interestingly, the yellow and red modules were significantly correlated with SN and TSW, whereas the turquoise and blue modules were correlated with seed and protein content. 


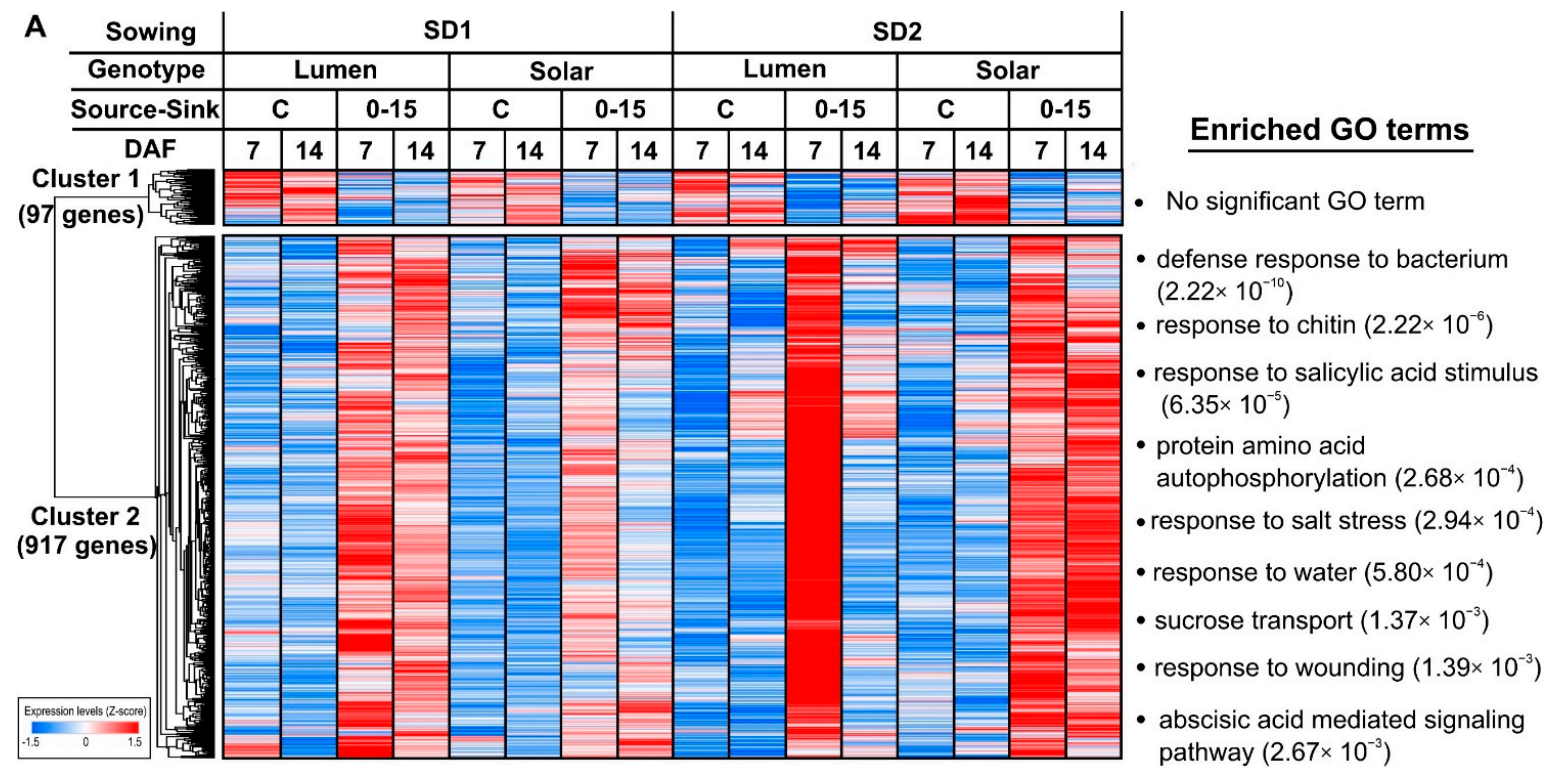

B

Sucrose transport

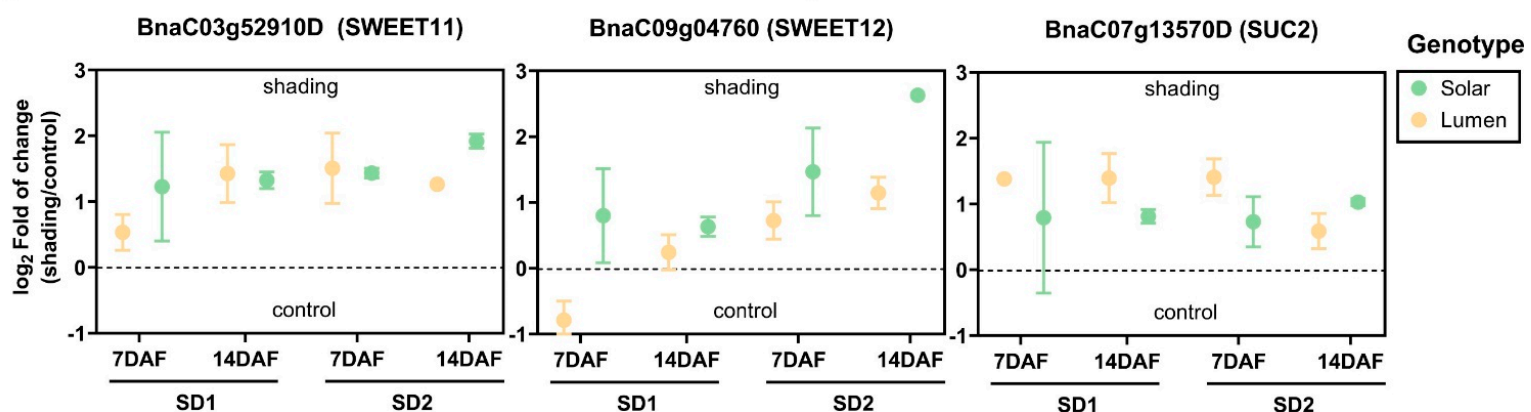

C

Seed weight genes

BnaC07g32280D (FER)

BnaA02g18890D (DA2)

BnaA01g24090D (ETR2)
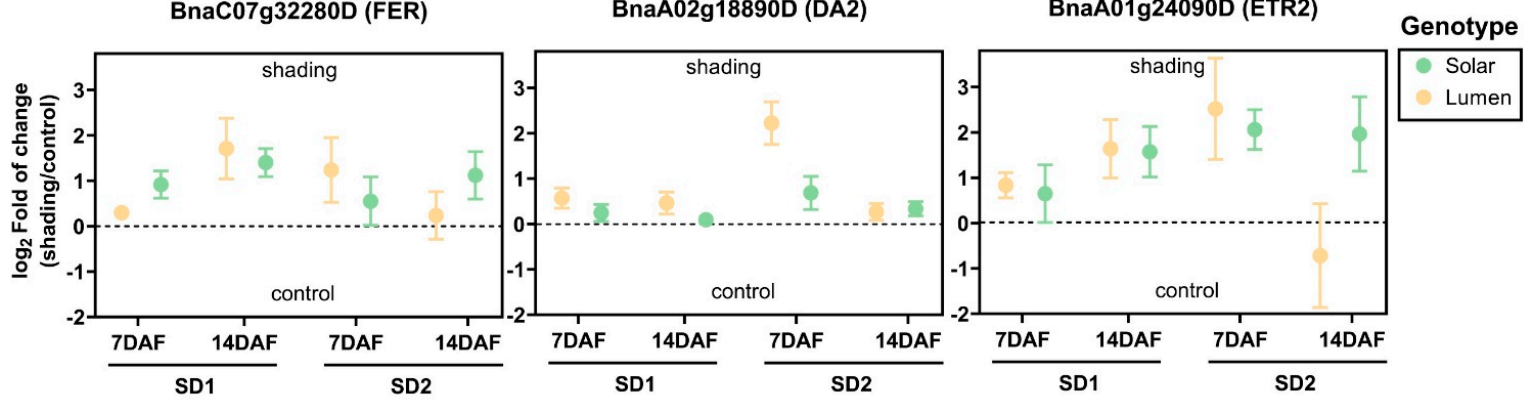

Figure 3. Reduction in the source-sink ratio during seed filling induces the expression of genes involved in sucrose transport, seed weight, and stress response. (A) A heatmap showing the two major expression patterns of genes exclusively regulated by shading treatment. Hierarchical clustering was performed based on Pearson correlation distances and average linkage using Morpheus software [29]. Each column of the heatmap represents the average expression of three biological replicates. The gene expression values for each gene were normalized by Z-score transformation. The significant and nonredundant GO terms (adjusted $p$-value $<0.05$ ) of the biological process domain are represented on the right side of each cluster. GO term enrichment analysis was performed by a hypergeometric test using BiNGO software [28]. FDR-adjusted $p$-values are indicated for each GO term in brackets. (B) Expression profiles of three representative genes belongs to the GO term "sucrose transport". The dots represent the average $\log _{2}$ fold change between the shading and control samples obtained from normalized RNA-seq data, whereas bars indicate the standard error of the mean (SEM) of three replicates. The Arabidopsis ortholog of each rapeseed gene is indicated in brackets. (C) Expression profiles of three representative genes for which the orthologs in Arabidopsis are involved in seed weight regulation. The dots represent the average $\log _{2}$ fold of change between shading and control samples obtained from normalized RNA-seq data, whereas bars indicate the standard error of the mean (SEM) of three replicates. The Arabidopsis ortholog of each rapeseed gene is indicated in brackets. 


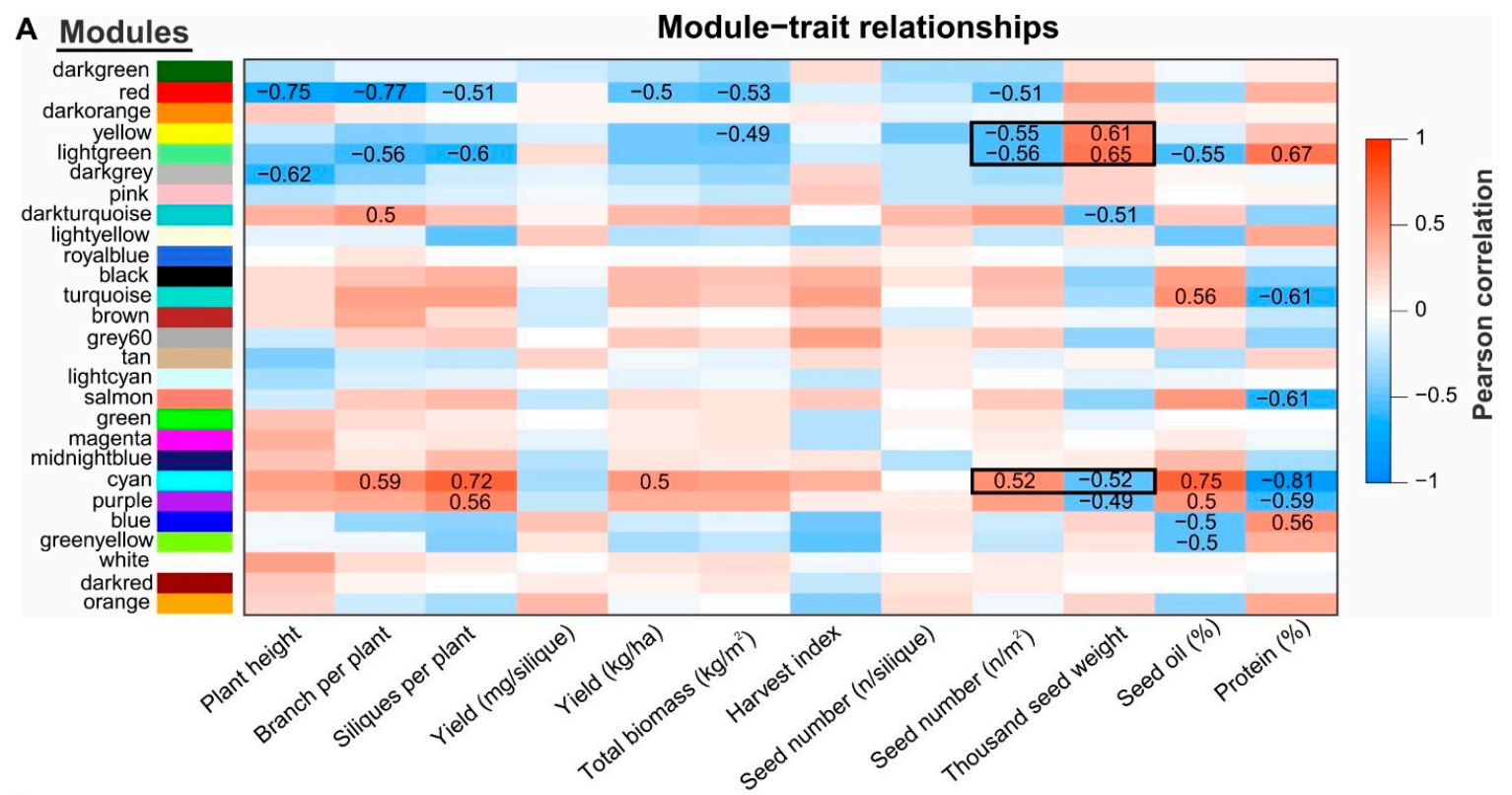

B
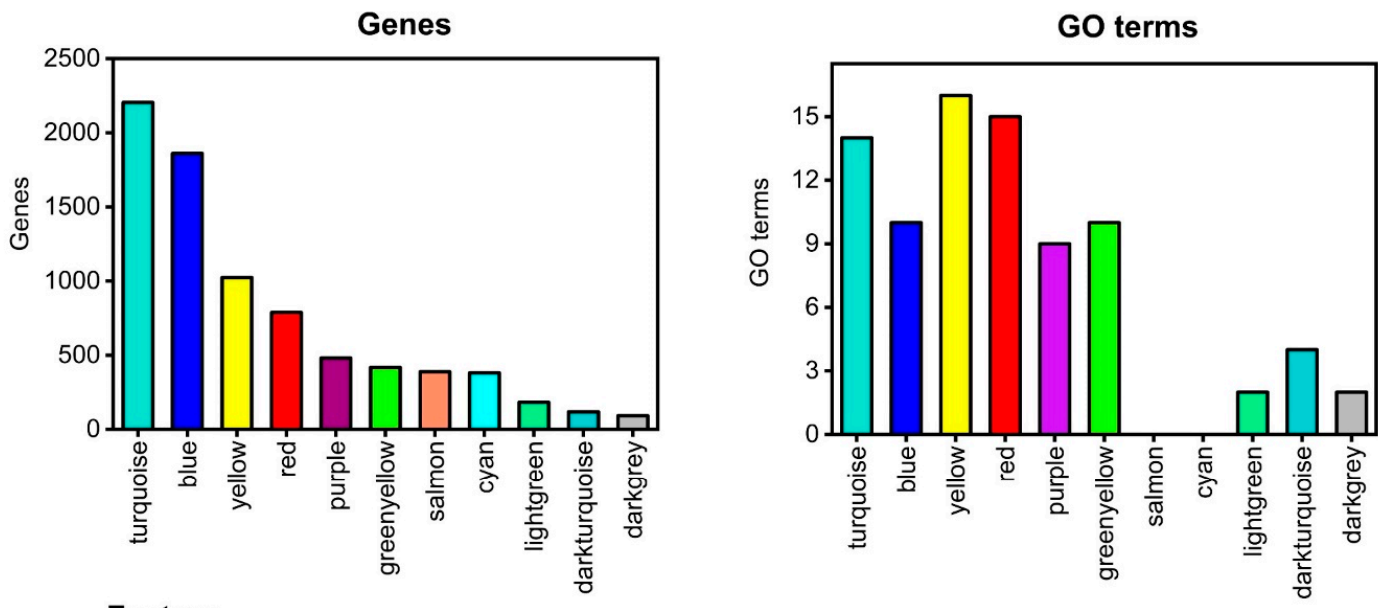

C

\section{Factors}
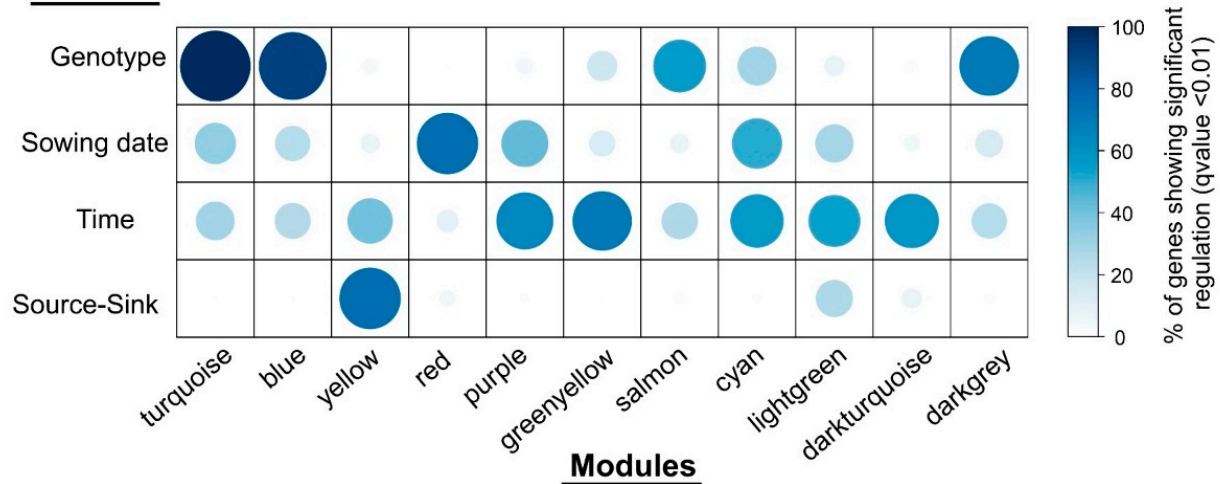

Figure 4. Weighted gene co-expression network analysis identified the modules associated with the SW and SN relationship at 7 DAF. (A) A heatmap showing the module-trait associations. Each row corresponds to a module eigengene, and each column corresponds to a trait. Only significant correlations ( $p$-value $<0.01$ ) are shown with numbers. Red and blue denote positive and negative correlations with gene expression, respectively. The agronomic traits were obtained from our previous work [16]. Modules significantly correlated with SW and SN are indicated with a black rectangle. (B) Histograms showing the number of genes (left) and GO terms (right) per co-expression module. Only modules significantly correlated with at least one agronomic trait are represented. (C) Balloon plot showing the percentage of genes in each module that are significantly regulated by each factor. 
A Modules

Module-trait relationships

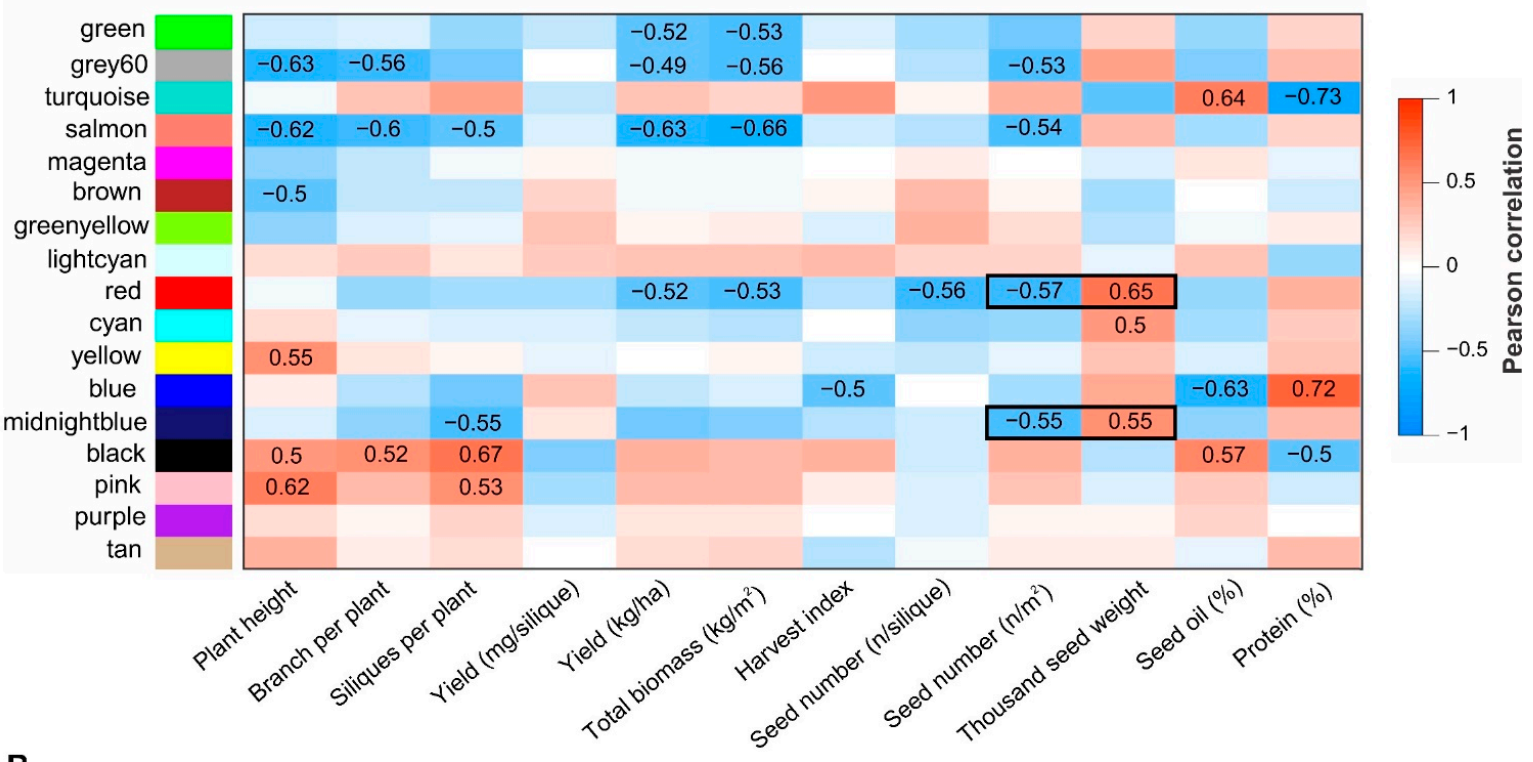

B
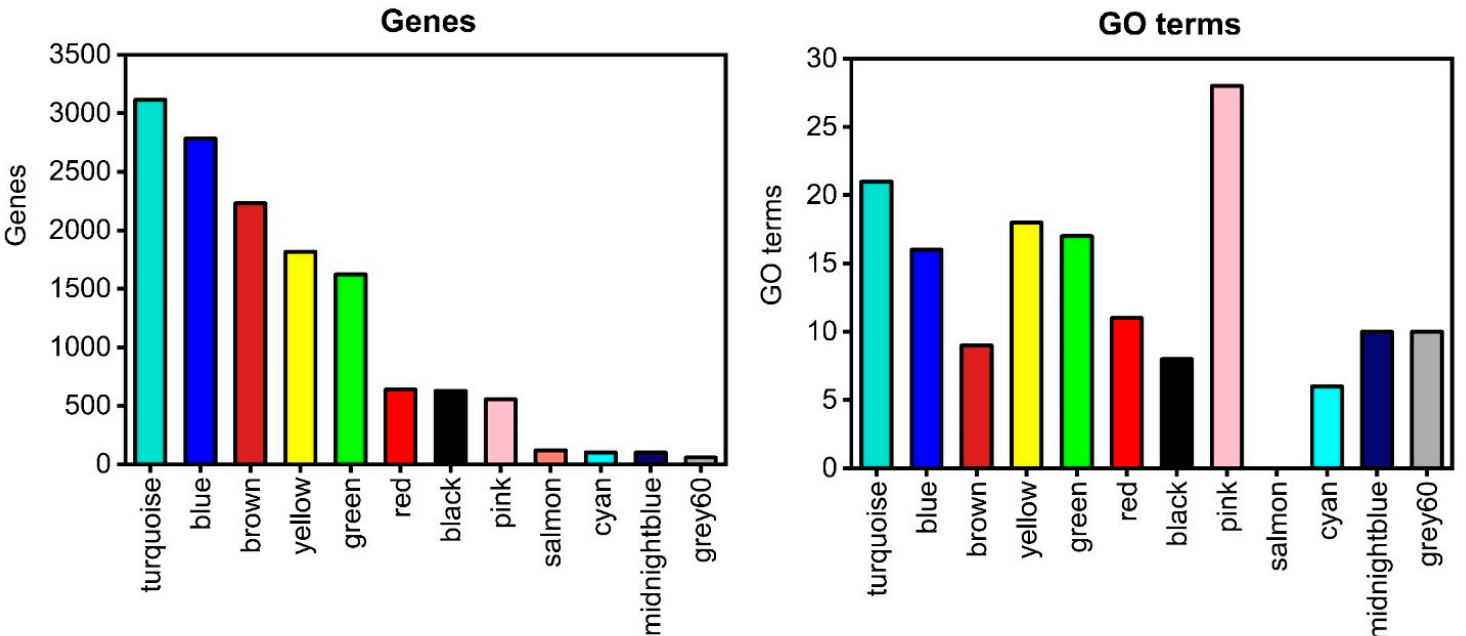

C

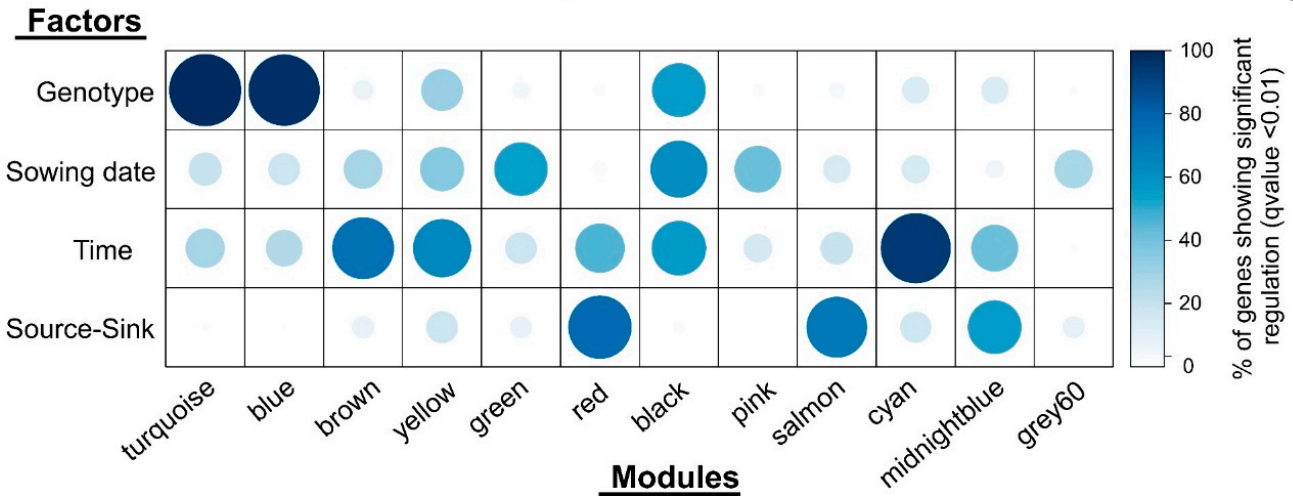

Figure 5. Weighted gene co-expression network analysis identified the modules associated with the SW and SN relationship at 14 DAF. (A) A heatmap showing the module-trait associations. Each row corresponds to a module eigengene, and each column corresponds to a trait. Only significant correlations ( $p$-value $<0.01$ ) are shown with numbers. Red and blue denote positive and negative correlations with gene expression, respectively. The agronomics traits were obtained from our previous work [16]. The modules significantly correlated with SW and SN are indicated with a black rectangle. (B) Histograms showing the number of genes (left) and GO terms (right) per co-expression module. Only modules significantly correlated with at least one agronomic trait are represented. (C) Balloon plot showing the percentage of genes in each module that are significantly regulated by each factor. 
An inverse relationship between SN and TSW was observed in the first case. The same inverse relationship was obtained for the second case. The GO enrichment analysis revealed that all of the modules correlated with physiological traits contained overrepresented biological processes (q-value $<0.01$ ) except for the case of the salmon and cyan modules (Figure 4B). An intersection analysis showed that more than $80 \%$ of genes from the turquoise and blue modules were significantly regulated by genotype according to the multivariate analysis (Figure 4C). The yellow module was the only co-expression module that showed a high percentage of genes regulated by the S-S ratio treatment $(>80 \%)$, whereas several small modules, such as green-yellow, cyan, or light green, were enriched in genes regulated by developmental time and sowing date (Figure $4 \mathrm{C}$ ).

In the case of the gene co-expression network constructed from the dataset of $14 \mathrm{DAF}$, we identified 12 out of 17 modules showing significant correlation $(p<0.01)$ with at least one physiological trait (Figure 5A). The GO enrichment analysis showed that eleven modules were enriched (q-value $<0.01$ ) in GO terms related to specific biological functions. The average size of these modules was 1148 genes, which is 1.6-fold higher than that in the early developmental time network. In fact, the number of modules with more than 500 genes was twice that in the previous time network ( 8 vs. 4) (Figure 5B). The gene co-expression modules of larger sizes (turquoise and blue) was significantly correlated with seed protein and oil concentration. Similar to the previous gene co-expression network, these modules were also enriched in genes regulated by genotype (Figure 5C).

\subsection{Identification of Regulatory Factors Associated with the Compensation of SW and SN Decreases by Source-Sink Restriction at Flowering}

The 7 DAF co-expression network showed that three modules positively correlated with SW and negatively with SN (yellow, light-green, and cyan; Figure 4). The light-green and cyan modules were discarded after further analysis due to their low enrichment in genes significantly regulated by S-S treatment and their low number of enriched GO terms (Figure 4B). In contrast, the yellow co-expression module showed a high percentage of significantly regulated genes in the S-S treatment $(>80 \%$, q-value $<0.01)$ and 16 significant enriched biological functions (Figure 4 , q-value $<0.01$ ). Therefore, we selected this module for further detailed analysis and to identify the candidate genes related to SW compensation. This module was composed of 1023 genes that are associated with several biological processes related to stress and phytohormone responses and signaling (Figure 6). Interestingly, we found that the yellow module is significantly enriched in the molecular function "transcription factor activity" with 96 genes (Figure 6C). The NAC family was the most prevalent family of TFs in this module with 25 genes (Figure 6D). In order to identify candidate TFs underlying SW increase, we used intramodular connectivity since the relationship between connectivity and gene essentiality is well known [34]. Specifically, a module membership (kME) threshold higher than 0.85 was selected as an indicator of high intramodular connectivity to identify hub genes. In addition, candidate TFs were ranked by their average gene significance (GS) with $\mathrm{SN}$ and $\mathrm{SW}$ traits. In this way, we identified BnaC09g47170D (NAC082), BnaA07g38140D (CRF6), and BnaC01g44850D (NGAL2) at the top TFs (Table S5). Interestingly, it has been demonstrated that NGAL2 regulates seed size in Arabidopsis [35,36]. Moreover, we found two TFs (NAC041 and IDD1) with high intramodular connectivity, which have been previously associated with cell wall biosynthesis and seed development in Arabidopsis, respectively [37,38]. As shown in Figure 6E, the mRNA levels of NAC082, NGAL2, NAC041, and IDD1 were positively correlated with SW and negatively correlated with SN $(p$-value $<0.001)$, indicating that these TFs might be involved in the control of the SW and SN relationship. 
A

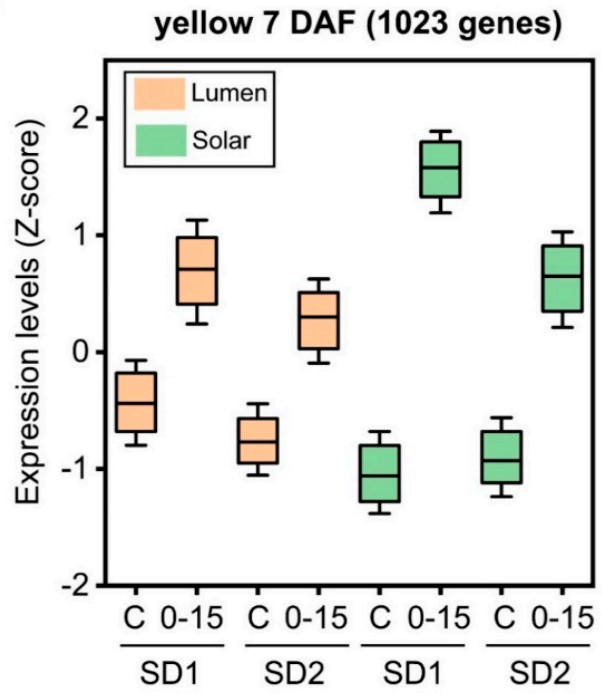

C

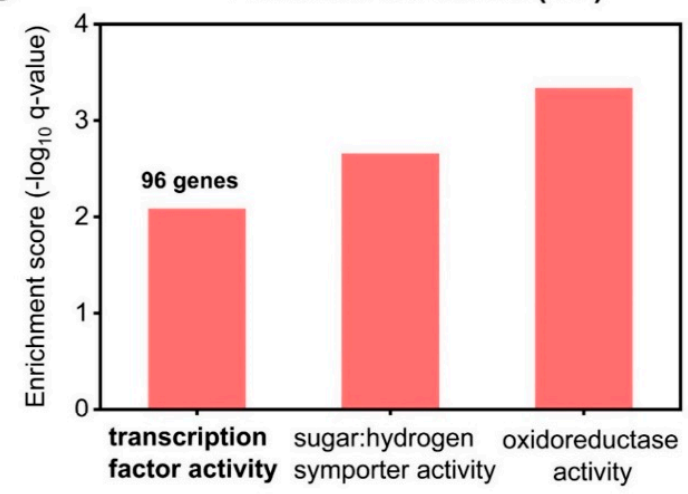

B

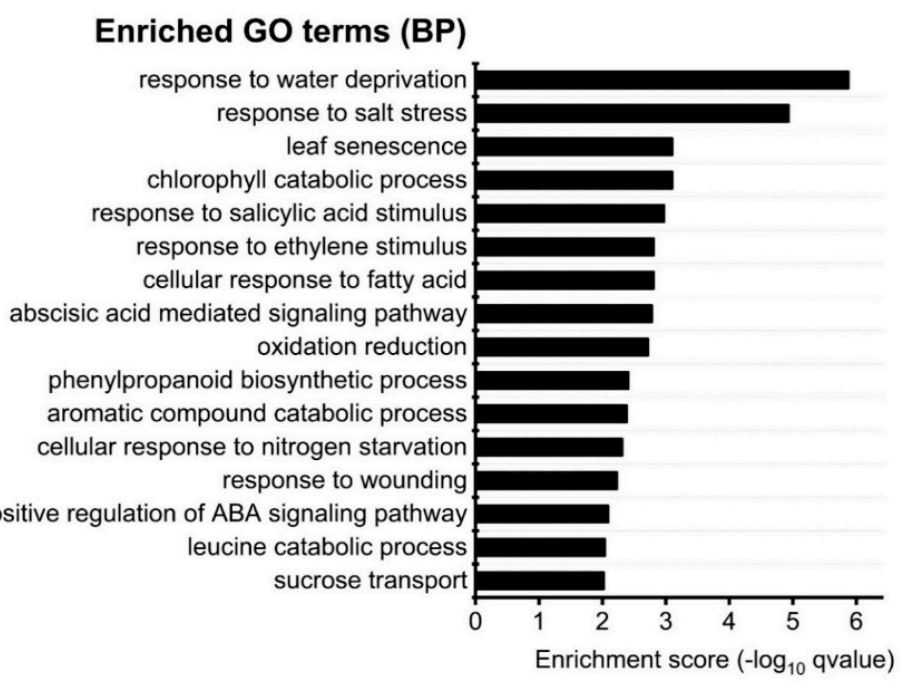

TF family

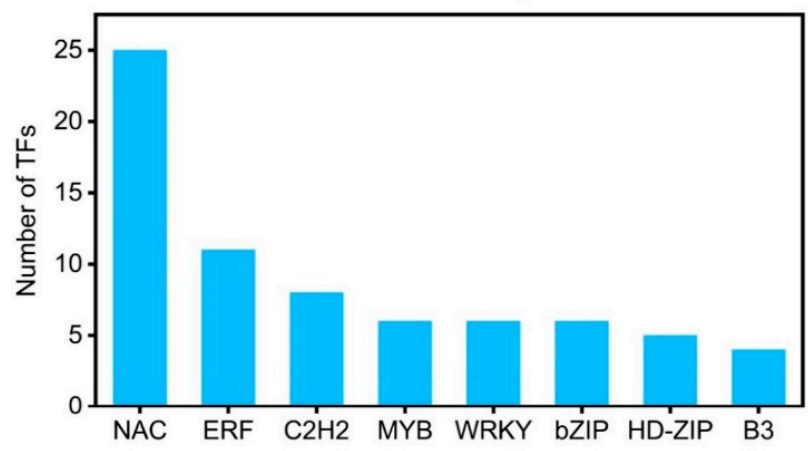

E

Seed number

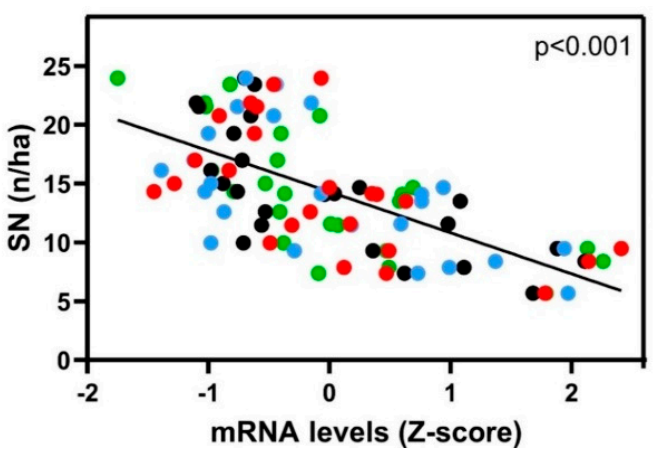

Seed weight

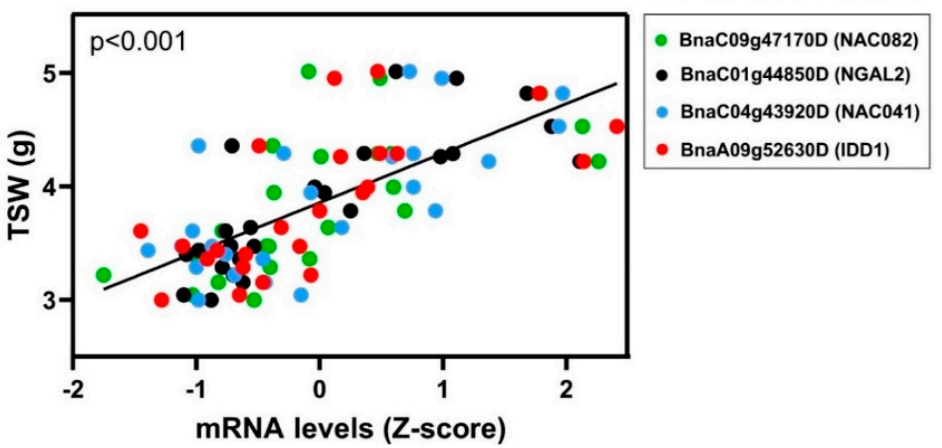

Figure 6. The yellow co-expression module of 7 DAF network is associated with the relationship between SW and SN. (A) Expression profiles of genes belonging to the yellow module. On each box, the central mark indicates the median, and the bottom and top edges of the box indicate the 25th and 75th percentiles, respectively. The whisker indicates the standard deviation of the expression data of all genes belonging to the yellow co-expression module. (B) GO term enrichment analysis of genes belonging to the yellow co-expression module performed by a hypergeometric test using the BiNGO software and the biological process domain [28]. (C) Enriched GO terms of the Molecular Function (MF) domain. The enrichment analysis was performed using the BiNGO software, as indicated above. (D) Distribution of the 96 transcription factors of the yellow module according to family. The transcription factors were classified following PlantTFDB4.0 database annotation [39]. (E) Relationships between the expression levels of the selected TFs and seed number (right) or seed weight (left). TFs were selected by taking into account their high intramodular connectivity and gene significance with SN and SW traits. 
In the case of the $14 \mathrm{DAF}$ co-expression network, we found that the red and midnight blue modules were significantly correlated with SW and SN (Figure 5A), although only the red module is highly enriched in genes significantly regulated by the S-S treatment ( $>80 \%$, Figure 5C). Interestingly, the expression profile of this module is similar to that of the yellow module of the 7 DAF co-expression network (Figure 7A); in fact, $53 \%$ of genes from the red module are shared with the yellow one. However, the size of the red module is about $40 \%$ lower than that of the yellow module of the 7 DAF co-expression network (638 vs. 1023 genes), suggesting that genes involved in the SW response are preferentially expressed at early stages of seed development. Accordingly, the total number of genes significantly correlated with SW and SN is 1586 genes at $7 \mathrm{DAF}$, which is two-fold higher than the case of 14 DAF network (739 genes). Overall, these results suggest that early stages of seed development are better predictors of final SW and SN.

A

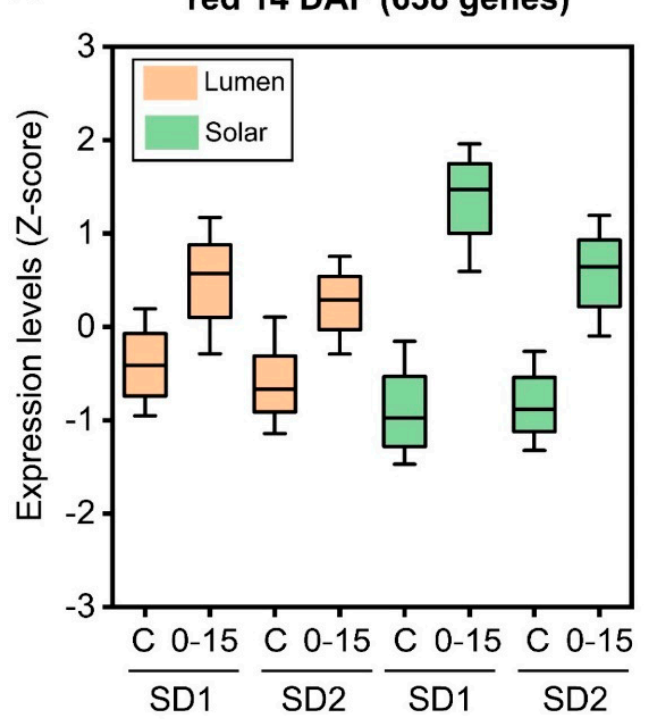

B

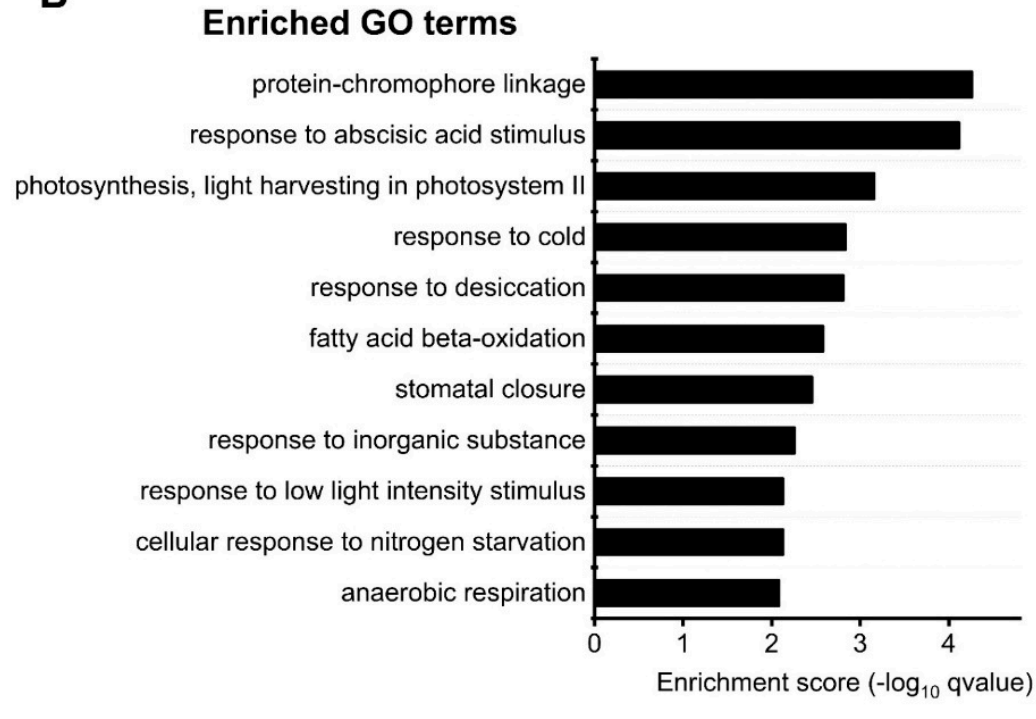

C

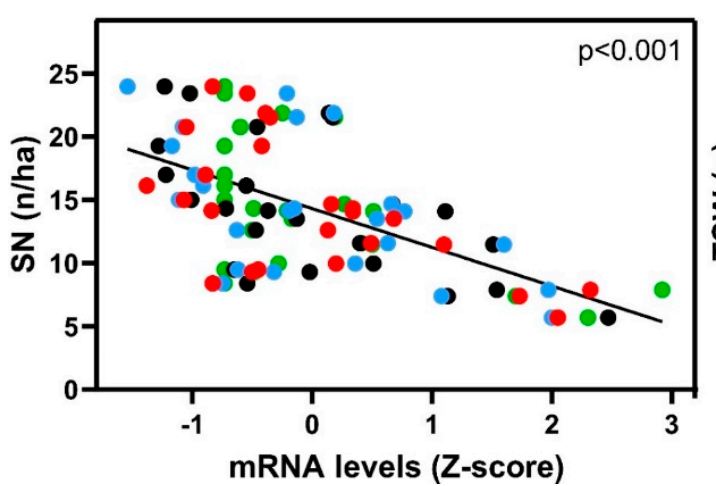

Seed weight

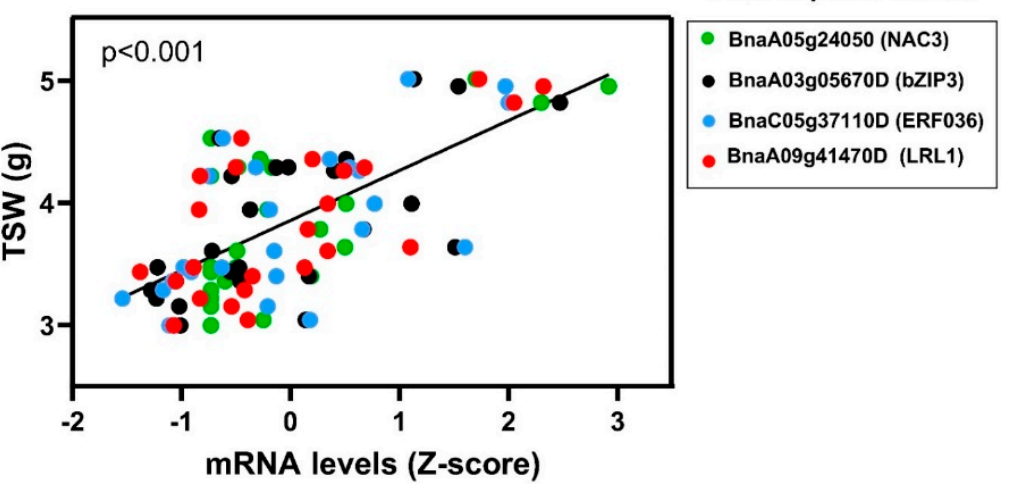

Figure 7. The red co-expression module of the 14 DAF network is associated with the relationship between SW and SN. (A) Expression profiles of genes belonging to the yellow module. On each box, the central mark indicates the median, and the bottom and top edges of the box indicate the 25th and 75th percentiles, respectively. The whisker indicates the standard deviation of the expression data of all genes belonging to the yellow co-expression module. (B) GO term enrichment analysis of genes belonging to the yellow co-expression module performed by a hypergeometric test using the BiNGO software and the biological process domain [28]. (C) Relationships between the expression levels of the selected TFs and seed number (right) or seed weight (left). TFs were selected by taking into account their high intramodular connectivity and gene significance with $\mathrm{SN}$ and SW traits. 
In addition, the GO term enrichment analysis reveals that "protein-chromophore linkage", "response to abscisic acid stimulus", and "photosynthesis" were the most significantly enriched biological functions associated with the red co-expression module (Figure 7B). To identify TF candidates for this module, we applied the same criteria used for the yellow module of 7 DAF. In this way, BnaA09g41470D (LRL1), BnaA05g24050D (NAC3), BnaA03g05670D (bZIP3), and BnaC01g02120D (HB40) were identified as top TFs in this module (Table S5). As shown in Figure 7C, several of these TFs (LRL1, bZIP3, and NAC3) are significantly correlated with SW and SN at 14 DAF, suggesting that these TFs might be SW and SN regulators in Brassica napus.

\section{Discussion}

Understanding the molecular mechanisms and genetic factors underlying complex agronomic traits, such as SW and quality, is vital for precise plant breeding [40]. It has been recently shown that transcript levels are useful for predicting complex traits such as plant height, flowering time, and grain yield in maize [41]. In fact, this study shows that transcriptome-based models have better prediction performance than genetic markers in the case of flowering time, suggesting that transcriptome data can provide a link to complex traits that cannot be readily captured at the sequence level [41].

In rapeseed, several transcriptomic studies have been carried out to identify candidate genes associated with seed oil content [42-46]. In contrast, very few studies have focused on the identification of genes associated with SW in Brassica napus [31,47]. Moreover, a comprehensive analysis that integrates transcriptome and physiological data under field conditions is still lacking, and even more scarce is information on the compensatory response of SW to a SN decrease. A critical issue for improving crop yield is the compensatory effect between SW and SN that has been observed in Brassica napus $[14,16]$. Despite the agronomic relevance of this issue, the molecular factors involved in the interaction between SW and SN are largely unknown in crops. In this study, we combined transcriptome sequencing with agronomic traits to obtain candidate genes associated with SW and SN under field conditions.

\subsection{Identification of Genes Related to Seed Weight Plasticity in Rapeseed}

A multifactorial analysis of RNA-seq data revealed that most of the significantly regulated genes (q-value $<0.01$ ) were only affected by one experimental factor, with developmental time and genotype being the most influential factors on the Brassica napus seed transcriptome under field conditions. Regarding the genes exclusively regulated by time, we found several significantly enriched biological processes related to protein biosynthesis and lipid metabolism at $7 \mathrm{DAF}$ and $14 \mathrm{DAF}$, respectively. These results are consistent with previous findings, showing that oil biosynthesis is initiated at about 14 DAF in rapeseed [45,48] while protein accumulation begins earlier [49]. These results indicate that our pipeline of multifactorial RNA-seq analysis captures relevant biological information regardless of environmental noise under field conditions.

We have previously shown that shading treatment negatively affects $\mathrm{SN}$ and positively affects SW, allowing for key compensation in seed yield [16]. In order to gain further insights into this compensation, we analyzed the expression patterns and functional identity of genes that were consistently regulated by the S-S treatment across genotype, developmental time, and sowing dates. Most of the genes exclusively regulated by the S-S treatment (928 out 1027) were induced by this factor. Interestingly, sucrose transport is one of the most significant enriched GO terms associated with genes regulated by the S-S treatment. Specifically, we identified two members of the SWEET family that were consistently induced by the shading treatment (Figure 3B). Previous functional studies demonstrated that SWEET proteins are key components of sugar translocation to seeds [50-52]. Mutation of AtSWEET11/12/15 in Arabidopsis thaliana severely affects seed development, including reduced seed weight, and reduced starch and lipid content [53]. A similar effect has been reported in rice, where the knockout of OsSWEET11 and 15 genes results in a complete loss 
of endosperm development $[51,54]$. Moreover, recent sequencing data from over 800 soybean genotypes revealed that a gene from the SWEET family (GmSWEET10a) has been selected and conferred simultaneous increases in soybean seed size and oil content [52].

Another remarkable example of a gene associated with seed weight and induced by S-S treatment is BnaA01g19380D, an ortholog of Arabidopsis DA2. This gene encodes a ubiquitin ligase that interacts with the ubiquitin receptor DA1 to synergistically regulate seed size in Arabidopsis [32]. Moreover, it has been demonstrated that the downregulation of an ortholog of DA1 in Brassica napus, BnDA1, resulted in a $21 \%$ increase in seed weight and $13 \%$ increase in seed yield per plant under field conditions [55]. A similar phenotype has been described in maize and wheat [56,57], indicating that the biological function of this gene is conserved in angiosperm plants. Moreover, it has been proposed that ZmDA1 improves the sugar imports into the sink organ and starch synthesis in maize kernels [56]. Therefore, it is possible that $D A 2$ could also be involved in the regulation of sugar translocation in response to changes in the S-S ratio.

\subsection{Transcription Factors Associated with SW and SN Response under Field Conditions}

Our study aimed to use bioinformatics analysis to identify genes related to agronomic traits with a special focus on SW-SN regulation, which might be a helpful target in yield improvement and yield stability in rapeseed and other crops. Specifically, we performed a WGCNA analysis from 48 RNA-seq samples obtained from seeds at 7 DAF and 14 DAF to identify gene co-expression modules significantly correlated with SW and SN (Figures 4 and 5, respectively). Interestingly, the yellow module of the 7 DAF network contains most of the genes significantly correlated with SW and SN. The most enriched molecular function was "transcription factor activity", indicating that this co-expression module is associated with the regulation of gene expression. NAC was the most abundant TF family of this module, with 25 members. NAC TFs are involved in diverse signaling and developmental events, including stress responses, senescence, and seed development [58,59]. Interestingly, NAC TFs have been described as controlling for several clues in seed development [59]. For instance, it has been recently shown that OsNAC25 and OsNAC26 bind to the promoters of important genes involved in the control of seed size in rice such as GW2, GW5, and DR11 [60]. Moreover, three NAC TFs (OsNAC020, OsNAC023, and OsNAC026) have been associated with $\mathrm{SW}$ in rice since their expression profiles during seed development vary among different accessions with contrasting seed size [61]. Taken together, these results suggest that NAC TFs might be relevant regulatory factors of the SW-SN relationship.

Next, we used the intramodular connectivity and trait correlation to identify candidate TFs from the yellow module of the 7 DAF network. An orthologue of Arabidopsis NAC082, BnaC09g47170D, was the TF with the highest average correlation to SW-SN. NAC082 belongs to the NAC domain family and was characterized for the first time in the context of xylem vessel differentiation after discovering that a master regulator of this developmental process, VND7, interacts with NAC082 in Arabidopsis [62]. More recently, it has been reported that NAC082 is a key regulator that connect the ribosomal defects induced by stress and cell proliferation $[63,64]$. Specifically, these studies showed that several stresses lead to an increase in NAC082 expression, which blocks tissue regeneration and delays seed germination. Taking into account this previous evidence, the reduction in source-sink ratio by shading treatments during seed filling triggers the expression of NAC082, which may block cell proliferation at early stages of seed development and may lead to a reduction in $\mathrm{SN}$.

It is important to note that several key regulators of seed size are also present at the top of our ranking of highly correlated TFs with SW-SN in the yellow module of the 7 DAF network. For instance, the orthologous gene of BnaC01g44850D in Arabidopsis, NGAL2 (third gene in Table S5), has been shown to regulate seed size by restricting cell proliferation in the integuments of ovules and by developing seeds [35]. The overexpression of NGAL2 dramatically decreases the seed size of Arabidopsis wild-type plants, whereas the disruption of this gene causes large seeds [35]. In fact, a gain-of-function mutant of the 
NGAL2 gene was identified as a suppressor of the large seed phenotype of DA1 [35], which is a key ubiquitin receptor for seed size determination [65]. Another TF involved in seed development identified in this co-expression module is IDD1 (orthologous to the rapeseed BnaA09g52630D gene). The seeds of the Arabidopsis IDD1 over-expressor lines were larger than those of wild-type plants due to an enlarged endosperm, higher seed weight in all the stages before seed maturity, and a significant delay in seed development [37].

Taken together, our study provides new insights into the molecular factors that regulate the SW and SN interaction in rapeseed. We identified several new TFs that have not been previously associated with $\mathrm{SN}$ and $\mathrm{SW}$ and were co-expressed with key regulators of seed size, such as NGAL2. The characterization of these TFs may improve the understanding of the regulatory mechanisms underlying the interaction between $\mathrm{SW}$ and $\mathrm{SN}$ in rapeseed and other crops, creating new pathways for crop yield improvements and yield stability via SW compensation to environmental conditions affecting SN.

\section{Materials and Methods}

\subsection{Field Experiment, Treatments, and Crop Management}

The field experiment and conditions were described in detail by Verdejo and Calderini [16]. Briefly, the field experiments on two sowing dates were carried out at the Austral Farming Experimental Station in Valdivia, Chile ( $\left.39^{\circ} 47^{\prime} \mathrm{S}, 73^{\circ} 14^{\prime} \mathrm{W}\right)$. In this experiment, three sources of variation were evaluated in rapeseed: (i) genotype (two adapted spring rapeseed hybrids: Lumen and Solar (chosen for their similar phenology and adapted to southern Chile)), (ii) sowing date (optimal and late sowing dates), and (iii) source-sink (S-S) ratios (control without manipulation and a reduced S-S ratio with black nets intercepting $75 \%$ of solar radiation from the beginning of flowering $(\mathrm{BBCH} 61)$ to 15 days after flowering (DAF)). The treatments were arranged in a split-split plot design with three replicates, where the sowing date was assigned to main plots, the $\mathrm{S}-\mathrm{S}_{\text {ratio }}$ was assigned to subplots, and the genotypes were assigned to sub-sub plots [16]. The rapeseed plants were sown at a plant density of 55 plants $\mathrm{m}^{-2}$.

\subsection{Phenology and Physiological Plant Sampling}

Crop development was followed twice a week in both experiments according to the $\mathrm{BBCH}$ phenological scale for rapeseed [66]. In order to determine the SN, TSW, and quality traits as seed oil and protein concentration, the seed samples were harvested in one lineal meter from the central rows of each plot at maturity (BBCH 89), when the seeds inside the siliques were dark and hard. The seed number was measured after oven drying the samples at $65{ }^{\circ} \mathrm{C}$ for $48 \mathrm{~h}$ using a seed counter (Pfeuffer GmbH, Kitzengen, Germany). Then, seed yield was measured and TSW was estimated as the ratio between seed yield and SN.

The oil concentration of seeds was determined by near infrared reflectometry (NIR) (Foss Infratec 1241, Hilleroed, Denmark) and the nitrogen concentration of seeds was measured using the Kjeldahl procedure [67]. The protein concentration of the seeds was calculated with a conversion factor of 5.8 [68]. The concentrations of both oil and protein are expressed on a dry matter basis.

\subsection{Seed Sampling and RNA Isolation}

In spring rapeseed, SW plasticity is maximized by shading within a time window from 0 to 15 days after the start of flowering [16]. Therefore, in order to elucidate the relevant modules or genes involved in SW determination, we chose two development stages to perform RNA-seq from seeds: in the middle and at the end of the source-sink treatments. The seed samples for the RNA-seq were collected from 5 plants per plot (25 siliques per plant from the bottom of the main raceme) in two development stages: 7 and 14 after the beginning of the shading treatment in three replicates across the different factors analyzed (genotypes, S-S ratios, and sowing dates). The seed samples were fast frozen in liquid nitrogen and then kept at $-80{ }^{\circ} \mathrm{C}$ until they were processed. The seeds were gridded 
using liquid nitrogen and a cold mortar and pestle. Total RNA extraction was performed using a method adapted for Brassica seeds [69] with $100 \mathrm{mg}$ of each sample and using PCR mini columns (NucleoSpin ${ }^{\circledR}$ Gel and PCR columns; Macherey-Nagel, Düren, Germany) in accordance with previously described protocols [70].

\subsection{RNA-Seq Analysis}

The RNA samples were shipped in dry ice to Novogene facilities in Sacramento, CA USA. RNA quality analysis, library construction, and sequencing were performed by Novogene (Beijing, China). The samples were sequenced using a $2 \times 150 \mathrm{bp}$ kit on an Illumina Novaseq 6000 aiming for $6 \mathrm{~Gb}$ per sample. The average Q20 per sample was 97.7\%, and that for Q30 was 93.8\%.

RNA-seq data analysis was performed as described by [71]. Briefly, sequenced reads were pseudo-aligned to the publicly available Brassica napus transcriptome obtained from Ensembl Plants using kallisto (v0.46) [25]. The transcript indices for kallisto were generated from rapeseed annotation version AST_PRJEB5043_v1, which includes 101,040 cDNAs (https: / / plants.ensembl.org/Brassica_napus/, accessed on 23 March 2021). A multivariate linear model to test whether the expression of a given gene could be explained by the S-S ratio, genotype, sowing date, or the interaction of these factors using the $\mathrm{R}$ package sleuth (v.0.30.0) [26]. This $\mathrm{R}$ package was also used to obtain the normalized expression data in transcripts per million (Table S6). In order to identify significantly regulated genes for each factor, we applied a q-value threshold of 0.01 . The intersection of the gene lists and their statistical significance were assessed using the SuperExactTest R package [27].

\subsection{Gene Co-Expression Network Construction}

Co-expression networks were built for two separate sample sets (7 and 14 DAF) using the method of weighted gene co-expression network analysis (WGCNA) [33]. For each network, we filtered out genes for which the counts were consistently low, with less than $5 \mathrm{tpm}$ in more than $90 \%$ of the samples. The count expression level of each gene was normalized using the method implemented in sleuth [26]. The soft-power threshold was chosen as the first power to exceed a scale-free topology fit index of 0.8 [72] for each network. The soft powers that fulfil this criteria were 9 for the 7 DAF network and 8 for the 14 DAF network. Then, the co-expression matrix was calculated using these power values, with a minimal module size of 30 and a merge cut height of 0.2 without PAM stage. Module-trait relationships were estimated using the association between the module eigengenes and the agronomic traits. For each expression profile, the gene significance (GS) was calculated as the absolute value of the association between the expression profile and each agronomic trait.

\subsection{Gene Ontology Enrichment Analysis}

Gene ontology (GO) terms for all of the B. napus genes were assigned based on A. thaliana orthologous genes according to Ensembl Plants in order to gain more informative enrichment results. BiNGO was then used to identify the significantly enriched GO terms (adjusted $p$-value <0.05) using a hypergeometric test [28], and redundancy between GO terms was reduced using REVIGO [73].

Supplementary Materials: The following are available online at https:/ / www.mdpi.com/article/10 .3390 /ijms22094449/s1, Figure S1: Box plot showing the total number of reads and pseudo-aligned reads in the B. napus transcriptome of all samples analyzed in this work. Figure S2: Expression profiles of three representative genes of the GO term "ribosome large subunit assembly" (A) and "Golgi organization" (B). Table S1: Genes significantly regulated by at least one factor with their corresponding q-values and the list of genes exclusively regulated by each factor. Table S2: Enriched GO terms for genes exclusively regulated by developmental time and S-S ratio. Table S3: Agronomics traits of each sample used in WGCNA analysis. Table S4: List of genes of the 7 and 14 DAF networks indicating their module membership. Table S5: Summary of the transcription factors of yellow and 
red modules of the 7 and 14 DAF network. Table S6: Normalized RNA-seq data in transcripts per million (tpm) scale.

Author Contributions: D.F.C., J.C., A.A.-M., F.M.C. and J.V. designed the study and experiments; J.V. and G.C.-P. performed the experiments; J.C. analyzed the data; J.C. wrote the paper. All authors have read and agreed to the published version of the manuscript.

Funding: This research was funded by grants from "Agencia Nacional de Investigación y Desarrollo de Chile (ANID)" FONDECYT 1170913 to D.C and FONDECYT 1190812 to J.C. J.C. was supported by ANID-Millennium Science Initiative Program-ICN17_022. F.M.C. was supported by FONDECYT 3190461. J.V. held a postgraduate scholarship from CONICYT 2017-21171384.

Institutional Review Board Statement: Not applicable.

Informed Consent Statement: Not applicable.

Data Availability Statement: The RNA-Seq datasets generated and analyzed during this study are available in the NCBI Gene Expression Omnibus (GEO) repository, accession GSE169511. All other data generated during this study are included in this published article and its Supplementary Materials.

Acknowledgments: We greatly appreciate the technical support from the staff at the Austral Farming Experimental Station (EEAA) of the Universidad Austral de Chile.

Conflicts of Interest: The authors declare no conflict of interest. The funders had no role in the design of the study; in the collection, analyses, or interpretation of the data; in the writing of the manuscript; or in the decision to publish the results.

\section{References}

1. Savadi, S. Molecular Regulation of Seed Development and Strategies for Engineering Seed Size in Crop Plants. Plant Growth Regul. 2018, 84, 401-422. [CrossRef]

2. Ray, D.K.; Mueller, N.D.; West, P.C.; Foley, J.A. Yield Trends Are Insufficient to Double Global Crop Production by 2050. PLoS ONE 2013, 8, e66428. [CrossRef]

3. Universidade Federal de Ouro Preto. UFOP Report on Global Market Supply 2017/2018; Universidade Federal de Ouro Preto: Ouro Preto, Brazil, 2019.

4. FAO. Food Outlook-Biannual Report on Global Food Markets; FAO: Rome, Italy, 2020.

5. FAOSTAT Crops Production 2021. 2021. Available online: http://www.fao.org/faostat/en/\#data/QC (accessed on 23 March 2021).

6. Peltonen-Sainio, P.; Kangas, A.; Salo, Y.; Jauhiainen, L. Grain Number Dominates Grain Weight in Temperate Cereal Yield Determination: Evidence Based on 30 Years of Multi-Location Trials. Field Crops Res. 2007, 100, 179-188. [CrossRef]

7. Beddington, J. Food Security: Contributions from Science to a New and Greener Revolution. Philos. Trans. R. Soc. B Biol. Sci. 2010, 365, 61-71. [CrossRef]

8. Rondanini, D.P.; Gomez, N.V.; Agosti, M.B.; Miralles, D.J. Global Trends of Rapeseed Grain Yield Stability and Rapeseed-to-Wheat Yield Ratio in the Last Four Decades. Eur. J. Agron. 2012, 37, 56-65. [CrossRef]

9. Sadras, V.O. Evolutionary Aspects of the Trade-off between Seed Size and Number in Crops. Field Crops Res. 2007, 100, 125-138. [CrossRef]

10. Slafer, G.A.; Savin, R.; Sadras, V.O. Coarse and Fine Regulation of Wheat Yield Components in Response to Genotype and Environment. Field Crops Res. 2014, 157, 71-83. [CrossRef]

11. Peltonen-Sainio, P.; Jauhiainen, L.; Sadras, V.O. Phenotypic Plasticity of Yield and Agronomic Traits in Cereals and Rapeseed at High Latitudes. Field Crops Res. 2011, 124, 261-269. [CrossRef]

12. Rondanini, D.P.; Mantese, A.I.; Savin, R.; Hall, A.J. Water Content Dynamics of Achene, Pericarp and Embryo in Sunflower: Associations with Achene Potential Size and Dry-Down. Eur. J. Agron. 2009, 30, 53-62. [CrossRef]

13. Castillo, F.M.; Vásquez, S.C.; Calderini, D.F. Does the Pre-Flowering Period Determine the Potential Grain Weight of Sunflower? Field Crops Res. 2017, 212, 23-33. [CrossRef]

14. Labra, M.H.; Struik, P.C.; Evers, J.B.; Calderini, D.F. Plasticity of Seed Weight Compensates Reductions in Seed Number of Oilseed Rape in Response to Shading at Flowering. Eur. J. Agron. 2017, 84, 113-124. [CrossRef]

15. Kirkegaard, J.A.; Lilley, J.M.; Brill, R.D.; Ware, A.H.; Walela, C.K. The Critical Period for Yield and Quality Determination in Canola (Brassica Napus L.). Field Crops Res. 2018, 222, 180-188. [CrossRef]

16. Verdejo, J.; Calderini, D.F. Plasticity of Seed Weight in Winter and Spring Rapeseed Is Higher in a Narrow but Different Window after Flowering. Field Crops Res. 2020, 250, 107777. [CrossRef]

17. Li, N.; Li, Y. Ubiquitin-Mediated Control of Seed Size in Plants. Front. Plant Sci. 2014, 5, 332. [CrossRef] 
18. Jiang, W.-B.; Huang, H.-Y.; Hu, Y.-W.; Zhu, S.-W.; Wang, Z.-Y.; Lin, W.-H. Brassinosteroid Regulates Seed Size and Shape in Arabidopsis. Plant Physiol. 2013, 162, 1965-1977. [CrossRef] [PubMed]

19. Li, N.; Li, Y. Maternal Control of Seed Size in Plants. J. Exp. Bot. 2015, 66, 1087-1097. [CrossRef]

20. Sun, X.; Shantharaj, D.; Kang, X.; Ni, M. Transcriptional and Hormonal Signaling Control of Arabidopsis Seed Development. Curr. Opin. Plant Biol. 2010, 13, 611-620. [CrossRef]

21. Wang, L.; Ruan, Y.-L. Regulation of Cell Division and Expansion by Sugar and Auxin Signaling. Front. Plant Sci. 2013, 4. [CrossRef]

22. Niu, Y.; Wu, L.; Li, Y.; Huang, H.; Qian, M.; Sun, W.; Zhu, H.; Xu, Y.; Fan, Y.; Mahmood, U.; et al. Deciphering the Transcriptional Regulatory Networks That Control Size, Color, and Oil Content in Brassica Rapa Seeds. Biotechnol. Biofuels 2020, 13, 90. [CrossRef] [PubMed]

23. Wang, X.; Freeling, M. The Brassica Genome. Front. Plant Sci. 2013, 4, 148. [CrossRef] [PubMed]

24. Calderini, D.F.; Castillo, F.M.; Arenas-M, A.; Molero, G.; Reynolds, M.P.; Craze, M.; Bowden, S.; Milner, M.J.; Wallington, E.J.; Dowle, A.; et al. Overcoming the Trade-off between Grain Weight and Number in Wheat by the Ectopic Expression of Expansin in Developing Seeds Leads to Increased Yield Potential. New Phytol. 2021, 230, 629-640. [CrossRef]

25. Bray, N.L.; Pimentel, H.; Melsted, P.; Pachter, L. Near-Optimal Probabilistic RNA-Seq Quantification. Nat. Biotechnol. 2016, 34, 525-527. [CrossRef]

26. Pimentel, H.; Bray, N.L.; Puente, S.; Melsted, P.; Pachter, L. Differential Analysis of RNA-Seq Incorporating Quantification Uncertainty. Nat. Methods 2017, 14, 687-690. [CrossRef] [PubMed]

27. Wang, M.; Zhao, Y.; Zhang, B. Efficient Test and Visualization of Multi-Set Intersections. Sci. Rep. 2015, 5, 16923. [CrossRef]

28. Maere, S.; Heymans, K.; Kuiper, M. BiNGO: A Cytoscape Plugin to Assess Overrepresentation of Gene Ontology Categories in Biological Networks. Bioinformatics 2005, 21, 3448-3449. [CrossRef] [PubMed]

29. Morpheus. Available online: https:/ / software.broadinstitute.org/morpheus/ (accessed on 9 March 2021).

30. Zhang, H.; Flottmann, S. Source-Sink Manipulations Indicate Seed Yield in Canola Is Limited by Source Availability. Eur. J. Agron. 2018, 96, 70-76. [CrossRef]

31. Li, N.; Song, D.; Peng, W.; Zhan, J.; Shi, J.; Wang, X.; Liu, G.; Wang, H. Maternal Control of Seed Weight in Rapeseed (Brassica Napus L.): The Causal Link between the Size of Pod (Mother, Source) and Seed (Offspring, Sink). Plant Biotechnol. J. 2019, 17, 736-749. [CrossRef]

32. Xia, T.; Li, N.; Dumenil, J.; Li, J.; Kamenski, A.; Bevan, M.W.; Gao, F.; Li, Y. The Ubiquitin Receptor DA1 Interacts with the E3 Ubiquitin Ligase DA2 to Regulate Seed and Organ Size in Arabidopsis. Plant Cell 2013, 25, 3347-3359. [CrossRef]

33. Langfelder, P.; Horvath, S. WGCNA: An R Package for Weighted Correlation Network Analysis. BMC Bioinformatics 2008, 9, 559. [CrossRef]

34. Gao, M.J.; Lydiate, D.J.; Li, X.; Lui, H.; Gjetvaj, B.; Hegedus, D.D.; Rozwadowski, K. Repression of Seed Maturation Genes by a Trihelix Transcriptional Repressor in Arabidopsis Seedlings. Plant Cell 2009, 21, 54-71. [CrossRef]

35. Zhang, Y.; Du, L.; Xu, R.; Cui, R.; Hao, J.; Sun, C.; Li, Y. Transcription Factors SOD7/NGAL2 and DPA4/NGAL3 Act Redundantly to Regulate Seed Size by Directly Repressing KLU Expression in Arabidopsis Thaliana. Plant Cell 2015, 27, 620-632. [CrossRef]

36. Chen, S.; Zhang, N.; Zhang, Q.; Zhou, G.; Tian, H.; Hussain, S.; Ahmed, S.; Wang, T.; Wang, S. Genome Editing to Integrate Seed Size and Abiotic Stress Tolerance Traits in Arabidopsis Reveals a Role for DPA4 and SOD7 in the Regulation of Inflorescence Architecture. Int. J. Mol. Sci. 2019, 20, 2695. [CrossRef]

37. Feurtado, J.A.; Huang, D.; Wicki-Stordeur, L.; Hemstock, L.E.; Potentier, M.S.; Tsang, E.W.T.; Cutler, A.J. The Arabidopsis C2H2 Zinc Finger INDETERMINATE DOMAIN1/ENHYDROUS Promotes the Transition to Germination by Regulating Light and Hormonal Signaling during Seed Maturation. Plant Cell 2011, 23, 1772-1794. [CrossRef] [PubMed]

38. Kim, W.-C.; Reca, I.-B.; Kim, Y.; Park, S.; Thomashow, M.F.; Keegstra, K.; Han, K.-H. Transcription Factors That Directly Regulate the Expression of CSLA9 Encoding Mannan Synthase in Arabidopsis Thaliana. Plant Mol. Biol. 2014, 84, 577-587. [CrossRef]

39. Jin, J.; Tian, F.; Yang, D.C.; Meng, Y.Q.; Kong, L.; Luo, J.; Gao, G. PlantTFDB 4.0: Toward a Central Hub for Transcription Factors and Regulatory Interactions in Plants. Nucleic Acids Res. 2017. [CrossRef]

40. Wang, B.; Li, J. Understanding the Molecular Bases of Agronomic Trait Improvement in Rice. Plant Cell 2019, 31, 1416-1417. [CrossRef] [PubMed]

41. Azodi, C.B.; Pardo, J.; VanBuren, R.; de los Campos, G.; Shiu, S.-H. Transcriptome-Based Prediction of Complex Traits in Maize. Plant Cell 2020, 32, 139-151. [CrossRef] [PubMed]

42. Xu, H.-M.; Kong, X.-D.; Chen, F.; Huang, J.-X.; Lou, X.-Y.; Zhao, J.-Y. Transcriptome Analysis of Brassica Napus Pod Using RNA-Seq and Identification of Lipid-Related Candidate Genes. BMC Genomics 2015, 16, 858. [CrossRef]

43. Shen, E.; Zhu, X.; Hua, S.; Chen, H.; Ye, C.; Zhou, L.; Liu, Q.; Zhu, Q.-H.; Fan, L.; Chen, X. Genome-Wide Identification of Oil Biosynthesis-Related Long Non-Coding RNAs in Allopolyploid Brassica Napus. BMC Genomics 2018, 19, 745. [CrossRef]

44. Xiao, Z.; Zhang, C.; Tang, F.; Yang, B.; Zhang, L.; Liu, J.; Huo, Q.; Wang, S.; Li, S.; Wei, L.; et al. Identification of Candidate Genes Controlling Oil Content by Combination of Genome-Wide Association and Transcriptome Analysis in the Oilseed Crop Brassica Napus. Biotechnol. Biofuels 2019, 12, 216. [CrossRef]

45. Shahid, M.; Cai, G.; Zu, F.; Zhao, Q.; Qasim, M.U.; Hong, Y.; Fan, C.; Zhou, Y. Comparative Transcriptome Analysis of Developing Seeds and Silique Wall Reveals Dynamic Transcription Networks for Effective Oil Production in Brassica Napus L. Int. J. Mol. Sci. 2019, 20, 1982. [CrossRef] 
46. Jiang, J.; Zhu, S.; Yuan, Y.; Wang, Y.; Zeng, L.; Batley, J.; Wang, Y.-P. Transcriptomic Comparison between Developing Seeds of Yellow- and Black-Seeded Brassica Napus Reveals That Genes Influence Seed Quality. BMC Plant Biol. 2019, 19, 203. [CrossRef] [PubMed]

47. Geng, X.; Dong, N.; Wang, Y.; Li, G.; Wang, L.; Guo, X.; Li, J.; Wen, Z.; Wei, W. RNA-Seq Transcriptome Analysis of the Immature Seeds of Two Brassica Napus Lines with Extremely Different Thousand-Seed Weight to Identify the Candidate Genes Related to Seed Weight. PLoS ONE 2018, 13, e0191297. [CrossRef] [PubMed]

48. Wan, H.; Cui, Y.; Ding, Y.; Mei, J.; Dong, H.; Zhang, W.; Wu, S.; Liang, Y.; Zhang, C.; Li, J.; et al. Time-Series Analyses of Transcriptomes and Proteomes Reveal Molecular Networks Underlying Oil Accumulation in Canola. Front. Plant Sci. 2017, 7. [CrossRef] [PubMed]

49. Jolivet, P.; Boulard, C.; Bellamy, A.; Valot, B.; d'Andréa, S.; Zivy, M.; Nesi, N.; Chardot, T. Oil Body Proteins Sequentially Accumulate throughout Seed Development in Brassica Napus. J. Plant Physiol. 2011, 168, 2015-2020. [CrossRef] [PubMed]

50. Sosso, D.; Luo, D.; Li, Q.-B.; Sasse, J.; Yang, J.; Gendrot, G.; Suzuki, M.; Koch, K.E.; McCarty, D.R.; Chourey, P.S.; et al. Seed Filling in Domesticated Maize and Rice Depends on SWEET-Mediated Hexose Transport. Nat. Genet. 2015, 47, 1489-1493. [CrossRef]

51. Yang, J.; Luo, D.; Yang, B.; Frommer, W.B.; Eom, J.-S. SWEET11 and 15 as Key Players in Seed Filling in Rice. New Phytol. 2018, 218, 604-615. [CrossRef] [PubMed]

52. Wang, S.; Liu, S.; Wang, J.; Yokosho, K.; Zhou, B.; Yu, Y.-C.; Liu, Z.; Frommer, W.B.; Ma, J.F.; Chen, L.-Q.; et al. Simultaneous Changes in Seed Size, Oil Content, and Protein Content Driven by Selection of SWEET Homologues during Soybean Domestication. Natl. Sci. Rev. 2020, 7, 1776-1786. [CrossRef]

53. Chen, L.-Q.; Lin, I.W.; Qu, X.-Q.; Sosso, D.; McFarlane, H.E.; Londoño, A.; Samuels, A.L.; Frommer, W.B. A Cascade of Sequentially Expressed Sucrose Transporters in the Seed Coat and Endosperm Provides Nutrition for the Arabidopsis Embryo. Plant Cell 2015, 27, 607-619. [CrossRef]

54. Ma, L.; Zhang, D.; Miao, Q.; Yang, J.; Xuan, Y.; Hu, Y. Essential Role of Sugar Transporter OsSWEET11 During the Early Stage of Rice Grain Filling. Plant Cell Physiol. 2017, 58, 863-873. [CrossRef]

55. Wang, J.-L.; Tang, M.-Q.; Chen, S.; Zheng, X.-F.; Mo, H.-X.; Li, S.-J.; Wang, Z.; Zhu, K.-M.; Ding, L.-N.; Liu, S.-Y.; et al. DownRegulation of BnDA1, Whose Gene Locus Is Associated with the Seeds Weight, Improves the Seeds Weight and Organ Size in Brassica Napus. Plant Biotechnol. J. 2017, 15, 1024-1033. [CrossRef] [PubMed]

56. Xie, G.; Li, Z.; Ran, Q.; Wang, H.; Zhang, J. Over-Expression of Mutated ZmDA1 or ZmDAR1 Gene Improves Maize Kernel Yield by Enhancing Starch Synthesis. Plant Biotechnol. J. 2018, 16, 234-244. [CrossRef] [PubMed]

57. Liu, H.; Li, H.; Hao, C.; Wang, K.; Wang, Y.; Qin, L.; An, D.; Li, T.; Zhang, X. TaDA1, a Conserved Negative Regulator of Kernel Size, Has an Additive Effect with TaGW2 in Common Wheat (Triticum Aestivum L.). Plant Biotechnol. J. 2020, 18, 1330-1342. [CrossRef] [PubMed]

58. Welner, D.H.; Deeba, F.; Lo Leggio, L.; Skriver, K. Chapter 13-NAC Transcription Factors: From Structure to Function in StressAssociated Networks. In Plant Transcription Factors; Gonzalez, D.H., Ed.; Academic Press: Boston, MA, USA, 2016; pp. 199-212, ISBN 978-0-12-800854-6.

59. Agarwal, P.; Kapoor, S.; Tyagi, A.K. Transcription Factors Regulating the Progression of Monocot and Dicot Seed Development. BioEssays 2011, 33, 189-202. [CrossRef] [PubMed]

60. Dwivedi, N.; Maji, S.; Waseem, M.; Thakur, P.; Kumar, V.; Parida, S.K.; Thakur, J.K. The Mediator Subunit OsMED15a Is a Transcriptional Co-Regulator of Seed Size/Weight-Modulating Genes in Rice. Biochim. Biophys. Acta Gene Regul. Mech. 2019, 1862, 194432. [CrossRef]

61. Mathew, I.E.; Das, S.; Mahto, A.; Agarwal, P. Three Rice NAC Transcription Factors Heteromerize and Are Associated with Seed Size. Front. Plant Sci. 2016, 7, 1638. [CrossRef]

62. Yamaguchi, M.; Ohtani, M.; Mitsuda, N.; Kubo, M.; Ohme-Takagi, M.; Fukuda, H.; Demura, T. VND-INTERACTING2, a NAC Domain Transcription Factor, Negatively Regulates Xylem Vessel Formation in Arabidopsis. Plant Cell 2010, 22, 1249-1263. [CrossRef] [PubMed]

63. Ohbayashi, I.; Lin, C.-Y.; Shinohara, N.; Matsumura, Y.; Machida, Y.; Horiguchi, G.; Tsukaya, H.; Sugiyama, M. Evidence for a Role of ANAC082 as a Ribosomal Stress Response Mediator Leading to Growth Defects and Developmental Alterations in Arabidopsis. Plant Cell 2017, 29, 2644-2660. [CrossRef]

64. Wang, W.; Ryu, K.H.; Bruex, A.; Barron, C.; Schiefelbein, J. Molecular Basis for a Cell Fate Switch in Response to Impaired Ribosome Biogenesis in the Arabidopsis Root Epidermis. Plant Cell 2020, 32, 2402-2423. [CrossRef]

65. Li, Y.; Zheng, L.; Corke, F.; Smith, C.; Bevan, M.W. Control of Final Seed and Organ Size by the DA1 Gene Family in Arabidopsis Thaliana. Genes Dev. 2008, 22, 1331-1336. [CrossRef]

66. Meier, U. Growth Stages of Mono- and Dicotyledonous Plants: BBCH Monograph; Blackwell Wissenschafts-Verlag: Berlin, Germany, 2018. [CrossRef]

67. Kirk, P.L. Kjeldahl Method for Total Nitrogen. Anal. Chem. 1950, 22, 354-358. [CrossRef]

68. Merrill, A.L.; Watt, B.K. Energy Value of Foods: Basis and Derivation; Human Nutrition Research Branch, Agricultural Research Service: Washington, DC, USA, 1973.

69. Graeber, K.; Linkies, A.; Wood, A.T.A.; Leubner-Metzger, G. A Guideline to Family-Wide Comparative State-of-the-Art Quantitative RT-PCR Analysis Exemplified with a Brassicaceae Cross-Species Seed Germination Case Study. Plant Cell 2011, 23, 2045-2063. [CrossRef] 
70. Yaffe, H.; Buxdorf, K.; Shapira, I.; Ein-Gedi, S.; Moyal-Ben Zvi, M.; Fridman, E.; Moshelion, M.; Levy, M. LogSpin: A Simple, Economical and Fast Method for RNA Isolation from Infected or Healthy Plants and Other Eukaryotic Tissues. BMC Res. Notes 2012, 5, 45. [CrossRef] [PubMed]

71. Canales, J.; Uribe, F.; Henríquez-Valencia, C.; Lovazzano, C.; Medina, J.; Vidal, E.A. Transcriptomic Analysis at Organ and Time Scale Reveals Gene Regulatory Networks Controlling the Sulfate Starvation Response of Solanum Lycopersicum. BMC Plant Biol. 2020, 20, 385. [CrossRef] [PubMed]

72. Zhang, B.; Horvath, S. A General Framework for Weighted Gene Co-Expression Network Analysis. Stat. Appl. Genet. Mol. Biol. 2005, 4, 17. [CrossRef] [PubMed]

73. Supek, F.; Bošnjak, M.; Škunca, N.; Šmuc, T. REVIGO Summarizes and Visualizes Long Lists of Gene Ontology Terms. PLoS ONE 2011, 6, e21800. [CrossRef] 